\title{
Prácticas emergentes en proyectos de espacio público: el caso de vía Argentina en ciudad de Panamá
}

\author{
José Antonio De Gracia \\ Universidad de Panamá \\ joseadgg@gmail.com
}

\section{Resumen}

Este artículo utiliza una intervención urbana en la ciudad de Panamá para reflexionar desde una perspectiva crítica y teórica sobre conceptos fundamentales en proyectos de espacio público.

Primero, se ilustran las funciones de la calle como estructura básica del espacio público. Se reconoce su importancia no solo como elemento de conectividad urbana, sino también como lugar de movimiento, de encuentro, de soporte y de creación de significados e identidades sociales urbanas.

En segundo lugar, se contextualiza nuestro caso de estudio: la renovación urbana de vía Argentina, una calle del centro urbano cuyo entorno se encontraba en un estado de deterioro como la mayoría de las calles en la ciudad, ocupada en gran medida por la presencia de vehículos. La intervención forma parte de una serie de proyectos urbanos que pretenden mejorar el tejido físico de la ciudad.

En un tercer apartado se inicia un análisis crítico en torno a las actuaciones sobre vía 
Argentina, empezando por la redistribución del espacio en la calle, la relación entre vehículos y peatones y la consolidación del espacio público.

Enseguida, se entra a discutir en detalle sobre los nuevos elementos primarios que se utilizan para la urbanización de la calle. Bordillo, vados, pavimento, rigola, imbornales, alcorques y bolardos pasan a formar parte de un sistema que debe mantener una relación coherente entre todas sus partes. Además, se hace énfasis en el diseño del suelo y la aplicación del pavimento como una herramienta para la construcción de una imagen e identidad urbana.

Finalmente, el artículo termina con un análisis de los parámetros de accesibilidad en el proyecto, relacionando el concepto con el uso del pavimento y la configuración en algunos tramos de la calle en plataforma única. El artículo utiliza un repertorio amplio de fotografía documental para contextualizar el caso de estudio.

Palabras clave: Diseño urbano; Espacio público; Pavimento; Accesibilidad universal; Plataforma única; Vía Argentina; Ciudad de Panamá

\section{Abstract}

This article uses an urban intervention in Panama City to discuss fundamental concepts in public space projects from a critical and theoretical perspective.

First, the functions of the street as a basic structure of public space are illustrated. Its importance is recognized not only as an element of urban connectivity, but also as a place of movement, encounter, support and creation of urban meanings and social identities.

Secondly, our case study is contextualized: the urban renewal of via Argentina, a street in the urban center whose environment was in a state of degradation like most streets in the city, largely occupied by the presence of vehicles. The intervention is part of a series of urban projects aimed at improving the physical structure of the city.

The third section begins a critical analysis of the actions on Via Argentina, starting with the redistribution of street space, the relationship between vehicles and pedestrians, and the consolidation of public space.

Next, we discuss in detail the new primary elements used for the urbanization of the street. Curbs, fords, pavement, rigola, gutters, tree surrounds and bollards become part of a system that must maintain a coherent relationship between all its parts. In addition, emphasis is placed on the design of the ground and the application of the pavement as a tool for the construction of an urban image and identity.

Finally, the article ends with an analysis of the parameters of accessibility in the project, relating the concept to the use of the pavement and the configuration in some sections of the street as a single platform. The article uses a wide repertoire of documentary photography to contextualize the case study.

Keywords: Urban design; Public space; Pavement; Universal accessibility; Single platform; Via Argentina; Panama City.

\section{Resum}

Aquest article utilitza una intervenció urbana a la ciutat de Panamà per reflexionar des d'una perspectiva crítica i teòrica sobre conceptes fonamentals en projectes d'espai públic.

Primer, s'il-lustren les funcions del carrer com a estructura bàsica de l'espai públic. Es reconeix la seva importància no només com a element de connectivitat urbana, sinó també com a lloc de moviment, de trobada, de suport i de creació de significats i identitats socials urbanes.

En segon lloc, es contextualitza el nostre cas d'estudi: la renovació urbana de via Argentina, un carrer de centre urbà l'entorn es trobava en un estat de deteriorament com la majoria 
dels carrers a la ciutat, ocupada en gran mesura per la presència de vehicles. La intervenció forma part d'una sèrie de projectes urbans que pretenen millorar el teixit físic de la ciutat.

En un tercer apartat s'inicia una anàlisi crítica al voltant de les actuacions sobre via Argentina, començant per la redistribució de l'espai al carrer, la relació entre vehicles i vianants i la consolidació de l'espai públic.

De seguida, s'entra a discutir en detall sobre els nous elements primaris que s'utilitzen per a la urbanització del carrer. Vorada, guals, paviment, rigola, embornals, escocells i pilons passen a formar part d'un sistema que ha de mantenir una relació coherent entre totes les parts. A més, es fa èmfasi en el disseny de terra i l'aplicació de l'paviment com una eina per a la construcció d'una imatge i identitat urbana.

Finalment, l'article acaba amb una anàlisi dels paràmetres d'accessibilitat en el projecte, relacionant el concepte amb l'ús de l'paviment i la configuració en alguns trams del carrer en plataforma única. L'article utilitza un repertori ampli de fotografia documental per contextualitzar el cas d'estudi.

Paraules clau: Disseny urbà; Espai públic; Paviment; Accessibilitat universal; Plataforma única; Via Argentina; Ciutat de Panamà

\section{Introducción. Sobre la calle y sus funciones}

La calle es la estructura básica del espacio público. Es ella la que ordena cada parte de la ciudad y es en ella donde convergen todos los elementos de la vida urbana, donde podemos compartir la vida ciudadana en común (Sudjic, 2017: 86; Harvey, 2013: 107) y donde tradicionalmente se desarrolla la opinión pública (Remesar y Ricart, 2013: 6-8). De tal forma, la calle adquiere un sentido político-cultural evidente. Este espacio donde se desarrolla la vida ciudadana está formado a su vez por una base material, por lo tanto, la calle puede entenderse también en un sentido físico con sus propias complejidades.

La función de la calle suele asociarse a simple conectividad-sobre todo desde el boom en el uso del automóvil-, pero cuando se establece una relación dialéctica entre ambos sentidos encontramos que la calle cumple un diverso repertorio de funciones. Desde la más básica está el movimiento, no asociado a la conectividad, sino al encuentro:

"En la escena espontanea de la calle yo soy a la vez espectáculo y espectador, y a veces, también, actor. Es en la calle donde tiene lugar el movimiento, de catálisis, sin los que no se da vida humana, sino separación y segregación, estipuladas e inmóviles. Cuando se han suprimido las calles [...] sus consecuencias no han tardado en manifestarse: desaparición de la vida, limitación de la "ciudad" al papel de dormitorio, aberrante funcionalización de la existencia." (Lefebvre, 1972: 25). 
El movimiento ocurre sobre una base tangible, por lo que la calle posee igualmente una función de soporte. Como lo enuncia Brandão (2014: 67), asumimos que esta sostiene unos elementos de "hardware urbano" como equipamientos, mobiliario y pavimento, es decir, lo físico; y también sostiene procesos y actividades, o el "software urbano", que se refiere a las dinámicas funcionales de uso y apropiación, es decir, lo relacional.

En términos de Lefebvre, la calle cumple además otra serie de funciones: función informativa, función de esparcimiento y función simbólica. Así, desde una base psicológica, Valera (2011: 12) establece que los seres humanos desarrollamos vínculos identitarios con nuestro entorno. De ahí subyace la importancia de la función simbólica del espacio público, como ente que constituye de manera colectiva las identidades sociales. En ese sentido, la calle y los elementos materiales que la configuran desempeñan un rol considerable en la construcción de los símbolos:

"Por su propia condición humana, estos vínculos [con el entorno] se articulan sobre la base de los significados que elaboramos y que "tiñen" los espacios físicos; como resultado de esta operación, pasan de ser "espacio" a ser "lugar" y adoptan un significado simbólico, sea este individual o social" (Valera, 2011: 13).

Ahora bien, hoy en día muchas ciudades se hallan en condiciones que suponen un obstáculo para el desarrollo apropiado de estas funciones, particularmente entre las ciudades latinoamericanas como ciudad de Panamá. La ciudad se ha organizado por décadas desde lo privado, y la calle, el espacio público, ha perdido valor al producirse como espacio remanente. Es decir, lo que queda luego de definir los usos de suelo (Cabrera, 2012: 35), donde el espacio público pasa de ser un elemento estructurante a elemento estructurado (Carrión, 2016: 14).

Es lo que Borja (2013: 39-41) ha llamado la tendencia del "urbanismo globalizado", en donde el desarrollo urbano genera ciudades fragmentadas de baja densidad, barriadas cerradas con muros, grandes centros comerciales y redes de autopistas que actúan como barreras. Sin embargo, al otro lado del espectro, señala Borja, encontramos también el "urbanismo ciudadano", cuya base es la significación del espacio público y la construcción de centralidades como una posible forma de recuperar la calle como un bien común (Harvey, 2013: 113). Ambos modelos pueden mezclarse en una sola ciudad, como parte de las contradicciones del desarrollo urbano actual.

En este contexto, el siglo XXI ve nacer intervenciones urbanas puntuales que pretenden establecer mejoras al tejido físico y construir nuevas identidades en muchas ciudades de la región. Un caso es el proyecto de espacio público de vía Argentina en la ciudad de Panamá, el cual, pese a su relativa novedad, se ha comenzado a utilizar como referente local de un modelo de espacio público "caminable" (algo que no puede decirse de muchas calles en Panamá). Se trata de un lugar que parece apuntar a 


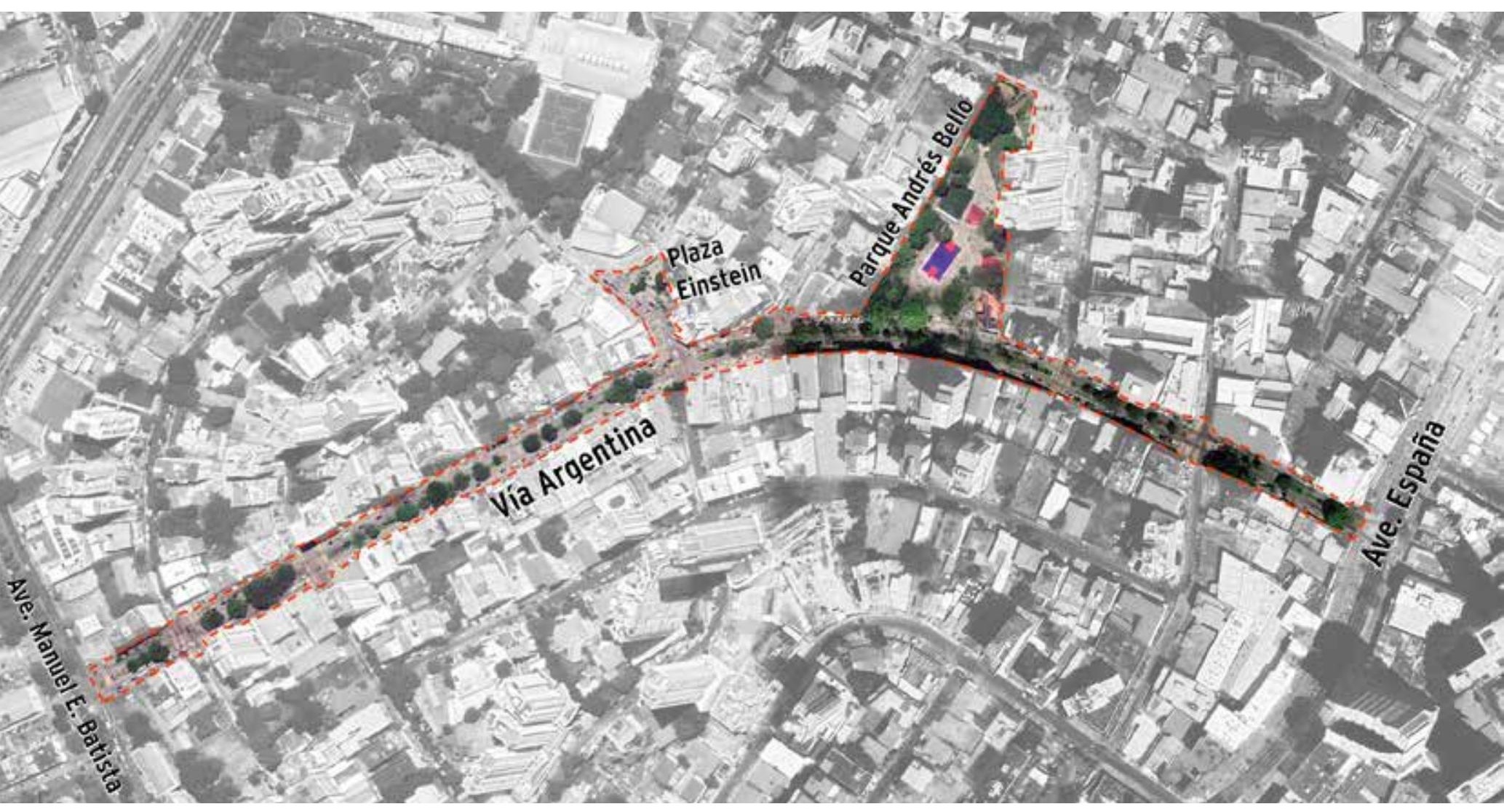

Fig. 1. Contexto urbano y acotación del proyecto de vía Argentina. Fuente: edición del autor sobre mapa de Google Earth.

convertirse en un ejemplo del urbanismo ciudadano ${ }^{1}$. De tal forma, la cualificación de la calle en vía Argentina constituye una buena oportunidad para estudiar las tendencias actuales del diseño urbano en nuestra región y reflexionar sobre conceptos fundamentales en el desarrollo de proyectos de espacio público.

\section{Contexto del proyecto de vía Argentina}

La creación de la Dirección de Planificación Urbana (DPU) en la Alcaldía de Panamá en el año 2014 significó un cambio radical en las políticas urbanas del municipio. La ciudad comenzó a trabajar en planes de ordenamiento a nivel local (una tarea que se hacía cada vez más urgente), se ampliaron los parámetros de participación ciudadana, y al mismo tiempo surgió una ola de proyectos urbanos orientados hacia la movilidad peatonal en toda la ciudad, particularmente en el centro. La renovación de la avenida República de Argentina, popularmente llamada vía Argentina, aparece en este contexto como uno de los principales proyectos de espacio público en el centro de la ciudad.

Vía Argentina es una calle del corregimiento de Bella Vista, ubicada en el centro del barrio de El Cangrejo, el cual fue urbanizado hacia la década de 1950. La calle se 1.- Aunque la intervención urbana también ha sido objeto de cuestionamientos por su supuesta intención de "revalorizar zonas atractivas para el sector inmobiliario" (Rodríguez, 2017: 124). 

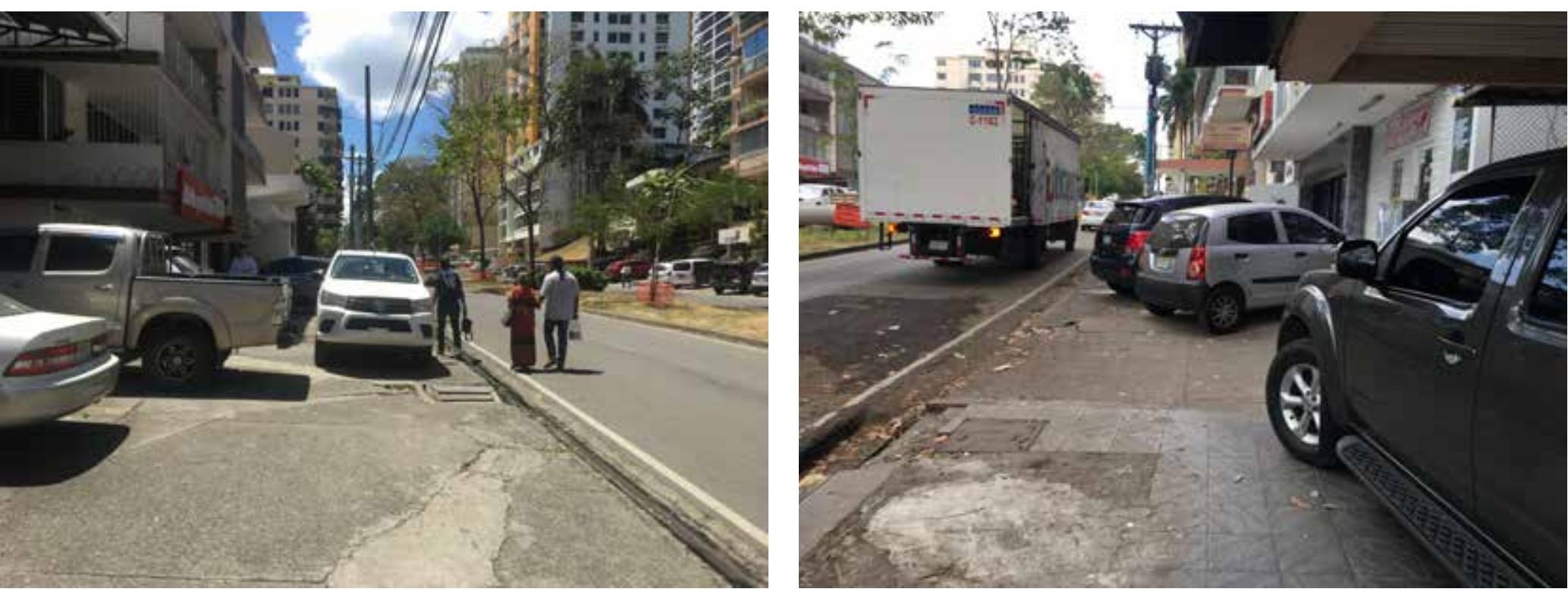

Fig. 2 y 3 . Vía Argentina antes de iniciar el proyecto de espacio público. Fuente: Jose Isturaín.

extiende a lo largo de 1 kilómetro aproximadamente, similar al recorrido de la Gran Vía en Madrid, o de La Rambla en Barcelona. Con una sección total de 25 metros se trata una calle mediana, pero importante ya que conecta la avenida España (una de las principales arterias de la ciudad) donde se ubica una estación del metro, con la avenida Manuel E. Batista y el campus central de la Universidad de Panamá.

La intervención urbana sobre el espacio público de vía Argentina comenzó en 2017, y el proyecto fue inaugurado oficialmente a inicios de 2021. Las obras incluyeron la mejora integral de la calle (aceras, calzada, arborización, soterramiento de cables, mejora de drenajes pluviales, etc.), además de la adecuación del parque Andrés Bello a los nuevos estándares de diseño que establece el proyecto, y la creación de la plaza Einstein (antes una rotonda vehicular).

El proyecto introduce también el modelo de la plataforma única en un tramo de su recorrido y en todas las intersecciones internas, un gesto que empieza a verse cada vez más en el espacio público de la ciudad. En este trabajo analizamos principalmente la intervención sobre la calle en sí, pero muchas de las próximas reflexiones pueden aplicarse también a estos espacios (parque y plaza) que acompañan el proyecto.

Finalmente, el proyecto incluyó la participación de los ciudadanos (bajo el mecanismo de consultas) durante el proceso de formalización de la propuesta, algo que antes no era una práctica común. Así, un informe de la Alcaldía de Panamá sobre la primera consulta ciudadana realizada en 2015 recogió las principales preocupaciones de los vecinos y el diagnóstico de los proyectistas con respecto a los problemas que presentaba la calle.

Entre varias cosas, uno de los asuntos más relevantes por resolver era el mal estado en el que se encontraban las aceras y su constante obstrucción no solo por basureros, comercios y más, sino también por vehículos que la utilizaban como estacionamiento de manera improvisada. De hecho, en ocasiones no existían aceras. Su espacio 
correspondiente solía ser tratado como un plano inclinado continuo que nacía en la calzada y se extendía hasta la fachada de los edificios. Una invitación a que los vehículos la ocuparan a su voluntad.

\section{La redistribución del espacio urbano}

En la calle tradicional solía existir espacio para distintas actividades como el juego, el ocio y la protesta, y para distintas velocidades como las del peatón y los vehículos (Miralles-Guasch y Cebollada i Frontera, 2003: 11). Sin embargo, durante una parte del siglo XX, con la creciente popularidad del automóvil como medio de transporte, las ciudades no solo se expandieron con este como eje conductor, sino que sus espacios también se configuraron en torno a su presencia. En el contexto panameño², esa realidad continúa manifestándose hasta el presente incluso en tiempos de pandemia (De Gracia, 2020: 10), aunque muchas ciudades hayan demostrado la necesidad de recuperar la calle y el espacio público como elementos que contribuyen al bienestar general de la población.

Los argumentos por un equilibrio más justo en la relación espacial de la calle son abundantes y además evidentes. Entre ellos, Piedade (2009: 120) argumenta que la mayoría de las "enfermedades" del espacio público están vinculadas a la ocupación excesiva por parte del vehículo privado. Por otro lado, Sudjic (2017: 85) explica que la experiencia de una calle se establece por las relaciones que existan entre peatones y vehículos. Harvey (2013: 117-118), desde el punto de vista de la creación de los bienes comunes urbanos, también comenta sobre el efecto de la presencia desmedida de los vehículos en las calles:

"Las calles congestionadas por el tráfico hacen ese espacio público particularcasi inútil hasta para los conductores, por no hablar de viandantes y manifestantes [...]. Este tipo de espacios urbanos no constituyen un bien común. Antes de verse inundadas de automóviles, no obstante, las calles sí solían serlo, como lugar de socialidad popular y de juego para los niños [...]. Pero ese tipo de bien común fue destruido y se convirtió en un espacio público dominado por el advenimiento del automóvil [...]".

Efectivamente, podemos asumir que reducir el protagonismo del automóvil y redistribuir el espacio urbano en la calle a favor del peatón se convierte en uno de los objetivos principales del proyecto de vía Argentina. A manera de análisis, vamos a iniciar con una comparación general entre el antes y el después para comprobar

2,. El propio Reglamento Nacional de Urbanizaciones de Panamá, actualizado en 2020, establece el enfoque del desarrollo urbano definiendo a la calle como una "vía pública de una ciudad o poblado, construida preferentemente para la circulación de vehículos". El reglamento se consultar en www.gacetaoficial.gob.pa bajo el número 29048 B. 
cuáles fueron las modificaciones y ganancias en la relación peatón-vehículo.

En primer lugar, la acción relevante más evidente en vía Argentina ha sido la unificación del pavimento en la acera desde el bordillo hasta donde la línea de propiedad lo permite ${ }^{3}$, resolviendo el problema de la interrupción en los itinerarios peatonales y diferenciando en cierta medida el espacio peatonal y el vehicular. Sobre este aspecto, Cullen (1971: 128) menciona la importancia del pavimento como un elemento capaz de producir una sensación de expansión y extensión, y además agrega que

"el suelo, el pavimento, puede y debe ser una superficie de unión, de contacto, entre y alrededor de los edificios. Si ello se consigue, dejará de ser la calle una simple franja de asfalto bordeada de aceras4. Podrá ser considerada como algo asociado a los edificios y producir, por medio de cambios de niveles, de escalas, de texturas y de general adecuación, un saludable efecto de sociabilidad y homogeneidad".

La constitución del pavimento de manera continua permitió eliminar los estacionamientos improvisados junto a las fachadas, los cuales utilizaban una parte del espacio del retiro frontal de los edificios y otra de la acera en mal estado. Estos se ordenaron en una franja de estacionamientos laterales junto a los bordillos en toda la calle, dejando un solo carril de tránsito en cada sentido. Ahora, si bien el proyecto pone en valor el espacio peatonal, vamos a ver que en realidad se consigue menos de lo que parece en términos de redistribución del espacio.

Anteriormente, vía Argentina distribuía su espacio en sección de la siguiente manera: aceras a cada lado de 3.50 metros (aunque discontinuas e interrumpidas), 4 carriles de tráfico de 3.00 metros cada uno ( 2 en cada sentido) y una mediana o isleta central de 6.00 metros (donde se ubica la mayoría de los elementos vegetales), resultando en una sección total de 25 metros. Esto quiere decir que la calle dedicaba $28 \%$ de su sección a usos peatonales, $48 \%$ a espacios destinados a los vehículos (aunque en la práctica solía ser más) y $24 \%$ de su sección como espacio residual equivalente a la mediana central.

Estas proporciones se mantienen en el proyecto de renovación, con leves variaciones en distintos tramos de la calle. La única variación notable es en la plataforma única, donde la mediana central se reduce 50 centímetros que se reparten entre aceras y calzada, pero mantiene una proporción casi idéntica a la anterior (ver fig. 8). Es decir, la distribución espacial en sección es la misma, pero se recuperan aquellos espacios peatonales invadidos con la consolidación de la acera.

3.- Los retiros frontales de algunos edificios, antes parte de los estacionamientos, ahora quedan como espacio residual que fragmenta la relación entre los planos de la calle (ver fig. 5). Se desvincula visualmente el plano de fachada y se distingue el dominio público del privado, aunque el retiro frontal es "espacio de acceso público". Para una reflexión más amplia sobre esta relación en la ciudad ver Remesar y Ricart (2013: 8-13).

4.- En el caso de vía Argentina podríamos decir que se trataba de una franja de asfalto bordeada de vehículos, estacionamientos improvisados y aceras inconexas o inexistentes. 


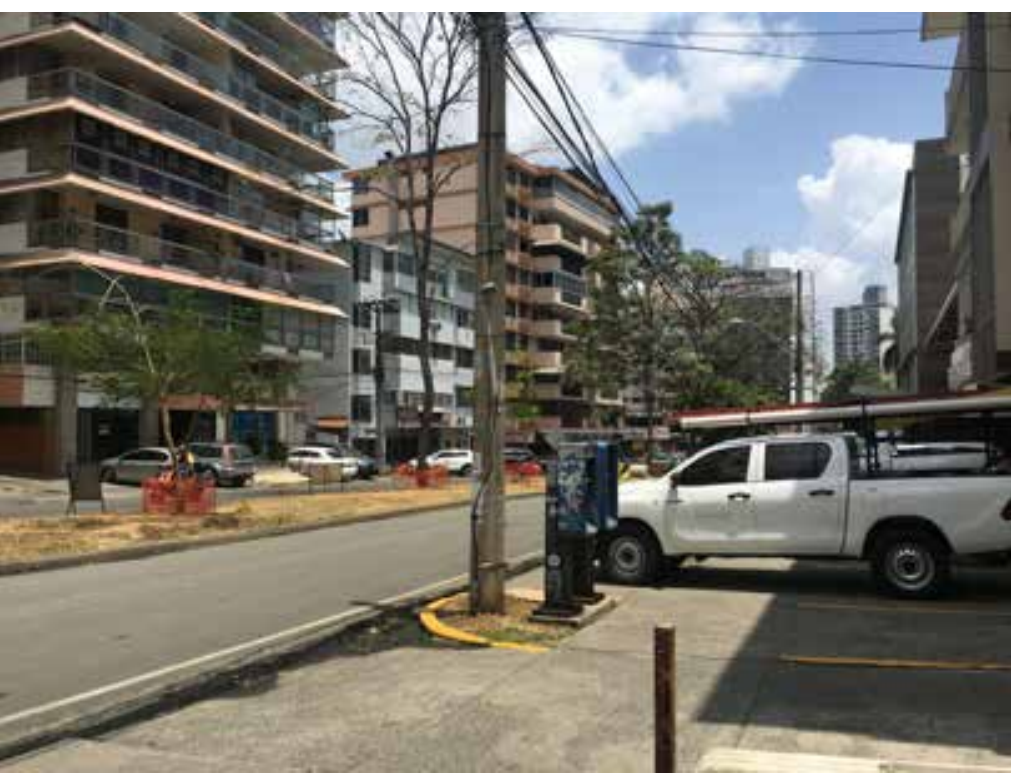

Figs. 4. Vía Argentina antes de iniciar el proyecto de espacio público. Fuente: Jose Isturaín.

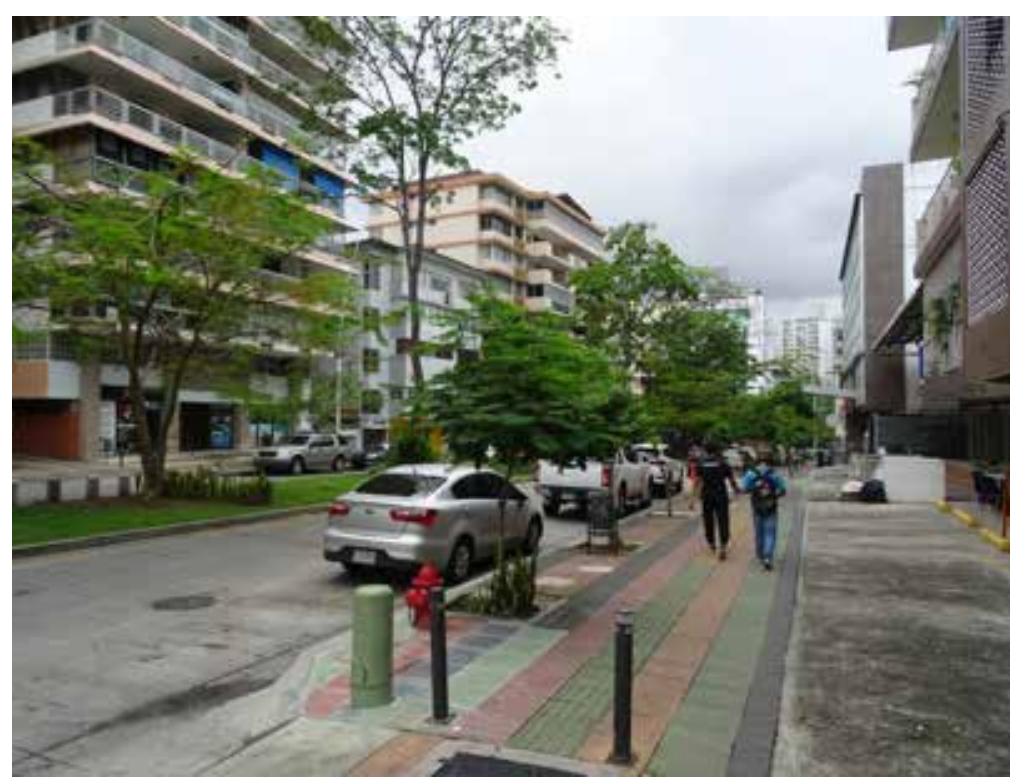

Fig. 5. Vía Argentina luego de haber concluido el proyecto de espacio público. Fuente: fotografía del autor.

En un contexto histórico, la preocupación por la distribución del espacio en la calle se remonta hasta el siglo XIX, como se pudo apreciar durante las transformaciones urbanas en el París de Haussmann que, bajo una lógica higienista, buscaban crear un nuevo orden en la sección de la calle:

"El espacio indiferenciado de la calle tradicional, por el que compiten en desorden peatones con diverso tipo de andadura, circulación rodada, puestos de mercancías, etc., da paso ahora a una repartición geométrica y clara a partir de los modos de circulación: en cada extremo, una acera dividida en dos pisos para canalizar los dos sentidos de la marcha [...]; a continuación, a cada lado, una calzada para coches y carruajes; y en el centro, cuatro filas de railes para los trenes que ahora cruzan París en todos los sentidos" (Calatrava, 2016: 57-58).

En una línea similar, Ildefonso Cerdá, quien era contemporáneo de Haussmann, llega a la conclusión de que el $50 \%$ del espacio en las calles de su propuesta para el nuevo ensanche de Barcelona debía estar destinado a los peatones y la otra mitad a los vehículos (Lecea, 2006: 43). Esto significaría que, por ejemplo, una calle con sección de 20 metros debería diseñarse, lo más cercano posible, con una calzada de 10 metros y aceras de 5 metros a cada lado y así lograr una sección más equilibrada.

Los principios de Cerdá sobre la división mitad-mitad se comenzaron a aplicar en Barcelona apenas hacia finales del siglo XX acompañados del lema "la calle no es una carretera" (Lecea, 2004: 7). Así, los efectos positivos luego de la transformación de los ejes representativos de la ciudad bajo este balance fueron el inicio de una mejora en el tejido físico del espacio público (Lecea, 2006: 44-52). Hoy, incluso, vemos procesos en algunas ciudades en los que un porcentaje todavía mayor de la calle es cedido a usos peatonales. Los gestores de la ciudad deben ahora procurar que la superficie de las 


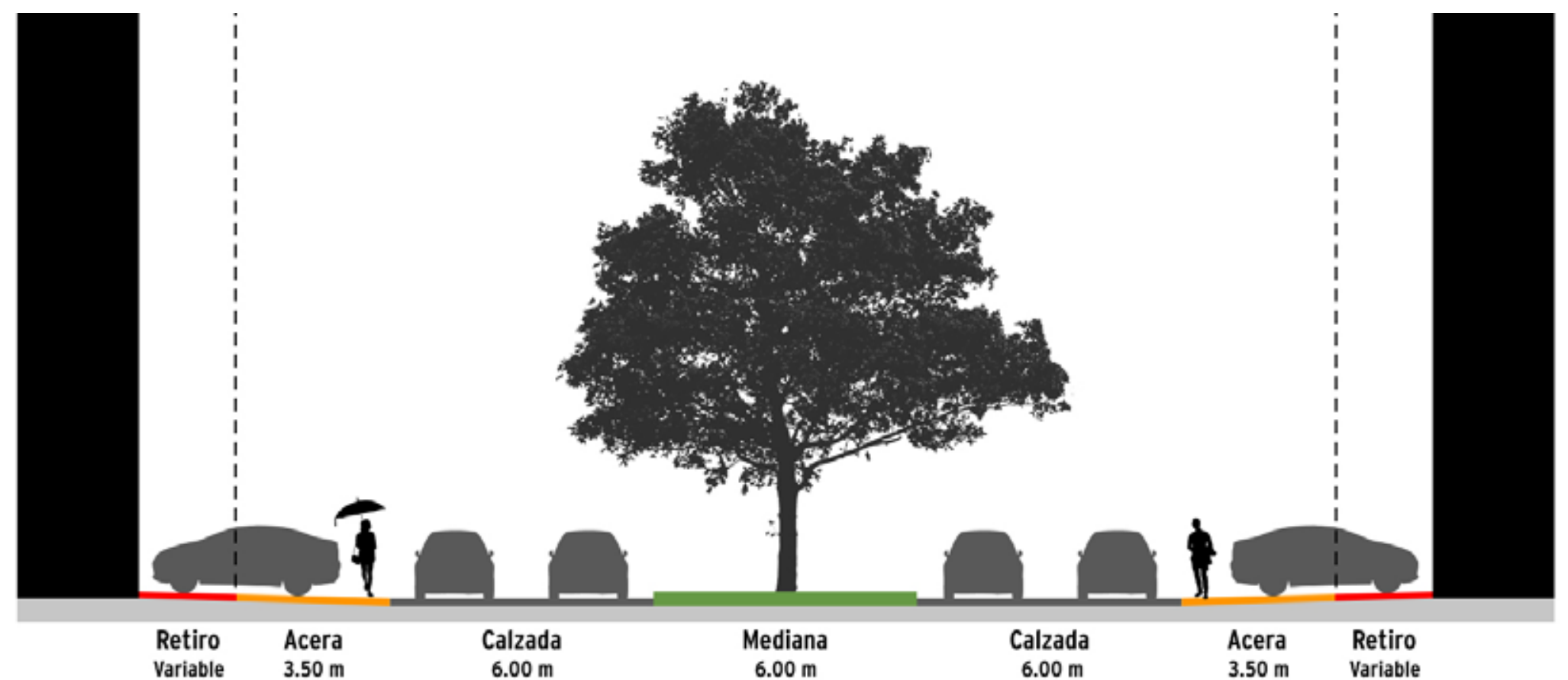

Fig. 6. Sección de calle previa al proyecto. Fuente: elaboración del autor.

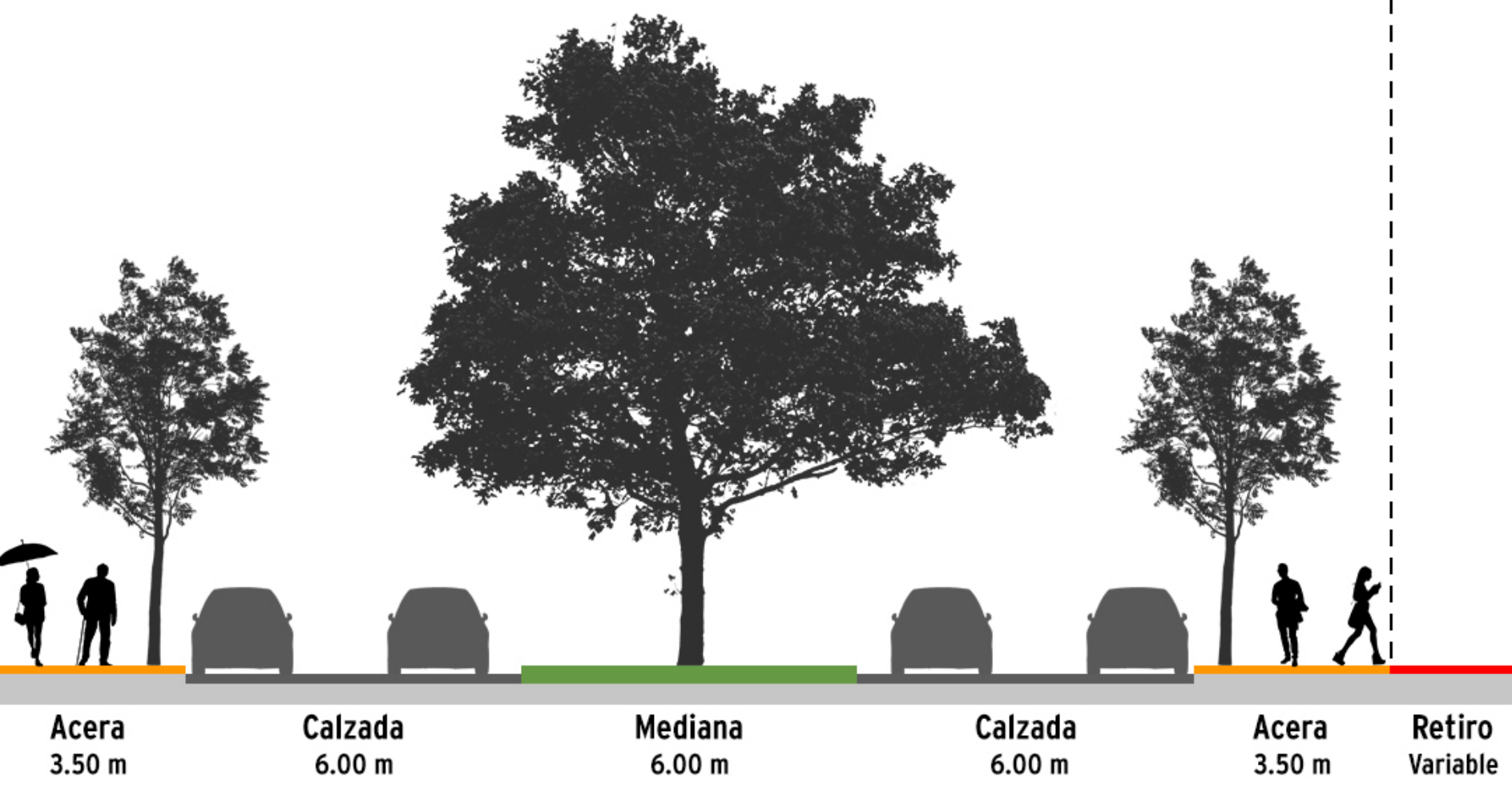

Fig. 7. Sección de calle convencional posterior al proyecto. Fuente: elaboración del autor. 


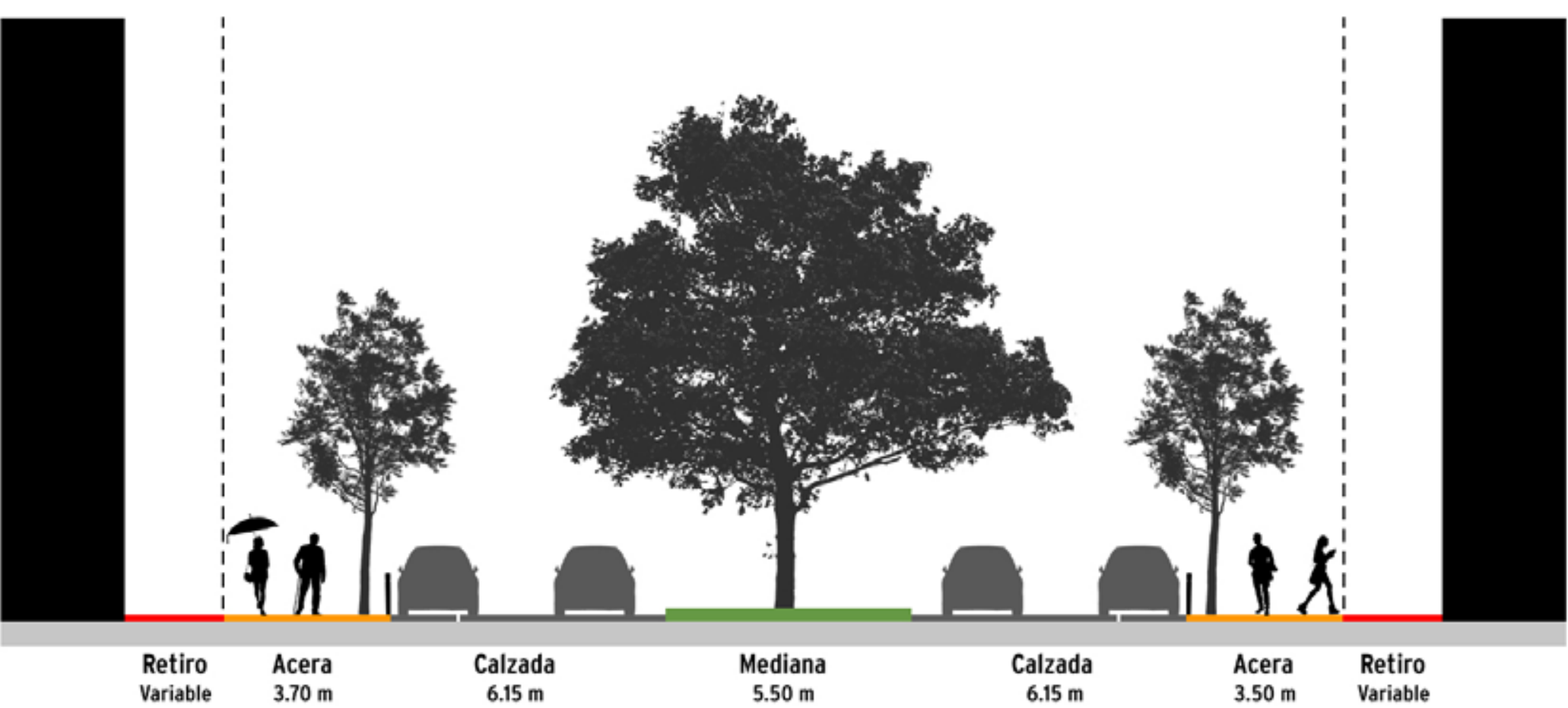

Fig. 8. Sección de calle en plataforma única luego del proyecto. Fuente: elaboración del autor.

aceras sea siempre superior al espacio destinado a la circulación rodada (Borja, 2013: 114). En el caso de vía Argentina, al mantener las proporciones anteriores en donde el vehículo sigue ocupando la mayoría del espacio, podemos decir que el proyecto se centró en recuperar un espacio invadido, pero no en ampliarlo bajo los conceptos de una redistribución más justa.

\section{Los elementos primarios de urbanización}

En el siguiente apartado se pasará a discutir sobre el sistema de elementos que componen el suelo en el proyecto de vía Argentina desde una perspectiva técnica y teórica que se apoyará principalmente, por su amplia cobertura y precisión, en los criterios de Lecea (2006: 32-59).

Partimos de la concepción de que en la construcción de la calle existe una serie de componentes característicos que no se limitan solo al pavimento, definidos por Lecea (2006: 33) como los "elementos primarios de urbanización", los cuales configuran el paisaje urbano y definen el espacio público de la ciudad: son los que "tiñen" el espacio físico común. Estos elementos son: bordillo, vados, pavimento, rigola 5 , imbornales, alcorques y bolardos.

Empezando por el bordillo ${ }^{6}$, Lecea define que, de acuerdo con la presencia o falta de este, la acera puede categorizarse de varias formas. Primero está la acera sin bordillo, en donde no se utiliza ningún elemento intermedio con la calzada. La otra solución,

5.- En Panamá no se utiliza la rigola, sino el bordillo-cuneta, similar al bordillo-rigola (Lecea, 2006: 38). 6.- En Panamá también se le conoce como "cordón". 


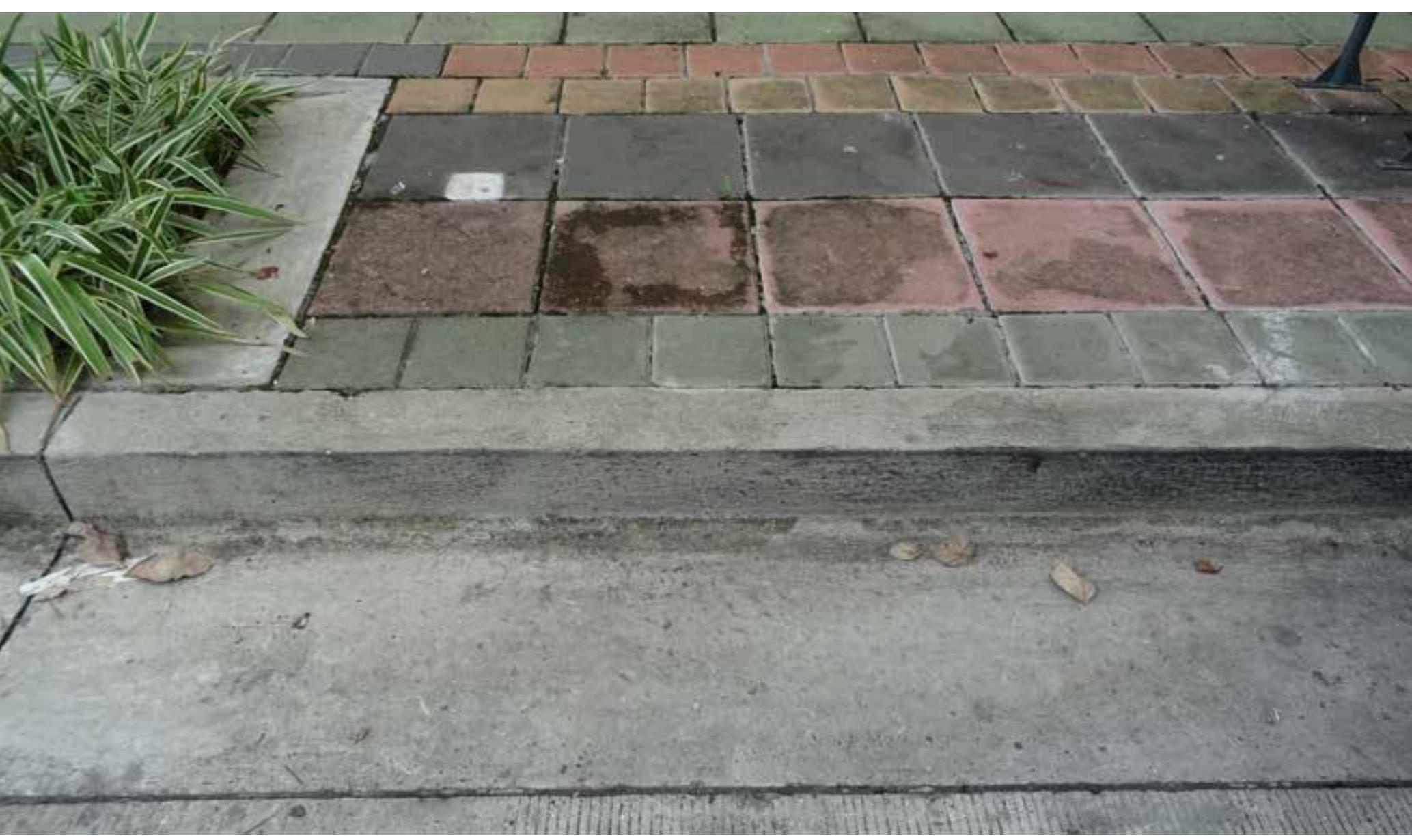

Fig. 9. Bordillo dentro del sistema de elementos primarios. Fuente: fotografía del autor.

más común cuando hay acera, es la del bordillo como un "elemento diferenciador":

"Desde un punto de vista estructural esta pieza actúa como pequeño murete de contención del desnivel entre acera y calzada, actúa también como amortiguador del impacto horizontal de las ruedas de los vehículos que aparcan o se desvian de su trayectoria y, en algunos casos, como confinador de la compactación de las capas del firme de la calzada" (Lecea, 2006: 38).

Los nuevos bordillos de vía Argentina son como los que encontramos en muchas otras partes de la ciudad en términos de materialidad y diseño. A diferencia de cómo se encontraban antes, ahora los bordillos se configuran a lo largo de toda la calle, desapareciendo solamente en los tramos donde aparece la plataforma única. Las piezas, fabricadas en hormigón, cubren una altura que va desde 15 a 20 centímetros, con anchura en su cara superior de entre 15 a 18 centímetros $^{7}$ para la pisada y una longitud variable entre juntas.

El bordillo se diferencia claramente de los colores del pavimento en la acera, pero su presencia como elemento diferenciador es débil por la similitud cromática y material con el hormigón rayado de la calzada. No está claro todavía si los bordillos serán

7.- Un estudio de las piezas in situ hizo notar que la dimensión de la cara superior era variable de tanto en tanto, posiblemente por su método de fabricación. 
pintados de blanco o amarillo, según disponibilidad de aparcamiento, como suele hacerse en el resto de la ciudad.

Siguiendo con los alcorques, estos tienen varias funciones. Una de ellas es contener las raíces de los árboles para que estas no dañen el pavimento. Pero su función más importante, según Lecea (2006: 39), es la de impedir la infiltración del agua utilizada para el riego en las capas estructurales del pavimento.

Los nuevos alcorques de vía Argentina poseen dimensiones de $1.20 \times 1.20$ metros de forma homogénea. Su establecimiento con nueva vegetación a lo largo de toda la calle representa una ganancia en términos de la calidad ambiental y urbana frente a las condiciones previas en donde no se encontraba este elemento primario, sino espacios sin vegetación o franjas continuas de grama junto a los bordillos en las pocas aceras que se veían. Según observaciones in situ, se encontró que la distancia entre alcorques es muy variable: pueden hallarse distanciados entre ellos desde 2 hasta 11 metros o más.

Una cualidad importante del alcorque es que este se inserta directamente al nivel del pavimento, formando parte de su sistema y generando un permanente diálogo con él. Por esta razón es recomendable que los alcorques respondan a la composición modular del pavimento para evitar posibles problemas de daño en las piezas y facilitar su mantenimiento8. Como bien lo advierte Lecea (2006: 39):

"Sobre pavimentos modulares el alcorque deberá ser un múltiplo de la división modular que se utilice, deberá cuidarse la solución de las aristas, pues el corte a inglete, más propio de la madera que de los materiales pétreos o moldeados, acabará erosionándose pronto, muchas veces durante el propio proceso de colocación".

A pesar de que las dimensiones de $1.20 \times 1.20$ metros ofrecen la posibilidad de establecer una relación con los pavimentos de 10 × 20, 20 × 20 y 40 × 40 centímetros en vía Argentina, se encontraron problemas en la implantación de los alcorques en el esquema modular del suelo 9 Esto da como resultado que algunas piezas del pavimento hayan tenido que ser recortadas, afectando la integridad estructural de la pieza y perjudicando la calidad estética del plano horizontal.

Siguiendo con los siguientes elementos primarios, Lecea (2006: 35) establece que tanto el movimiento de personas y vehículos, como la circulación y recolección de las aguas son usos importantes que debe soportar una calle desde un punto de vista funcional. Se puede argumentar, incluso, que la misión física número uno del espacio público es la de recoger las aguas y llevarlas al sistema de alcantarillado (Pereira \& Henrich, 2019: 13). Esto se consigue con un sistema de elementos que trabajan en torno a la rigola o la cuneta.

8.- Iglesias (2016: 9-18) provee una breve base teórica acerca del mantenimiento de los materiales en el espacio público desde el punto de vista de la limpieza y la sustitución de las piezas.

9.- Los planos de proyecto mostraban originalmente alcorques de 80 x $80 \mathrm{~cm}$ que no se llegaron a utilizar, lo que también permitía una buena relación modular con el pavimento. Estos pueden consultarse en www.panamacompra.gob.pa bajo el acto número 2016-5-76-0-08-LV-009249. 

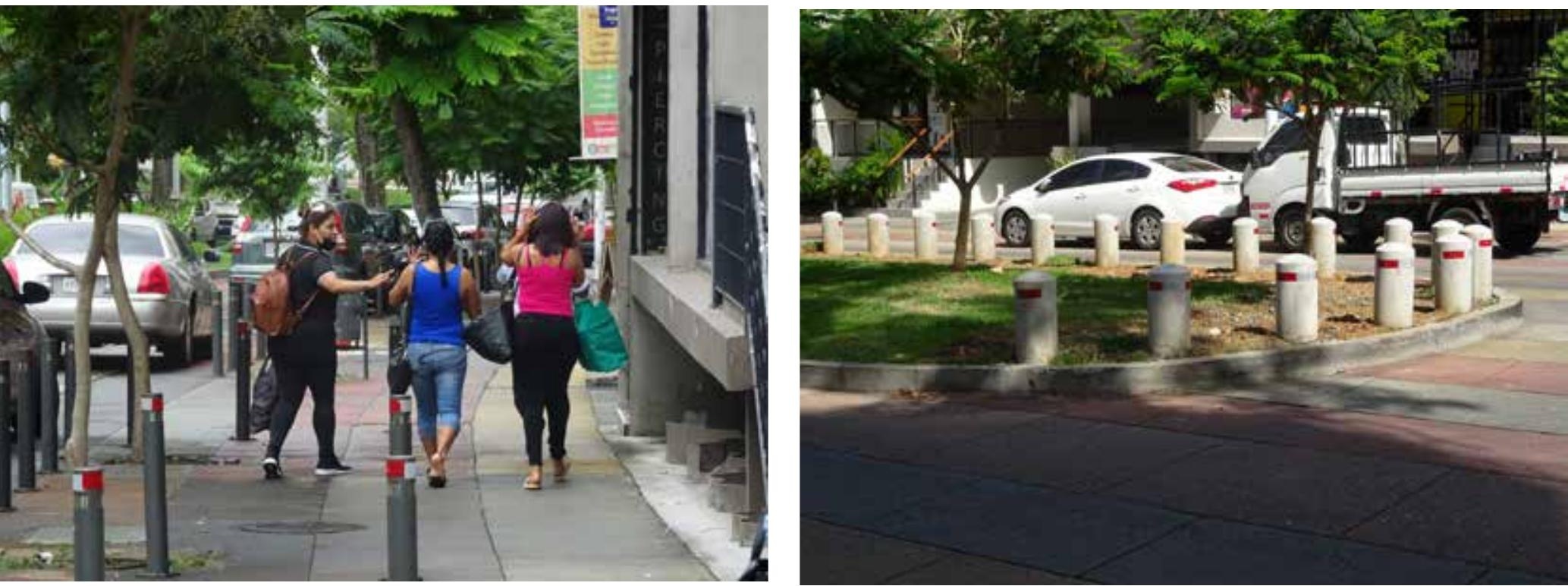

Fig. 13 y 14. A la izquierda, el bolardo aparece como un elemento dominante en el paisaje de la calle. A la derecha, bolardos de concreto instalados en la mediana central. Fuente: fotografía del autor.

En vía Argentina se utilizan principalmente para segregar los itinerarios peatonales de los vehiculares en los tramos donde aparece la plataforma única. En este caso, el bolardo se convierte en el reemplazo del límite vertical que convencionalmente estaría marcado por la diferencia de cota entre acera y calzada. Estos elementos tienen una altura de 80 centímetros y están separados entre ellos a 1.50 metros. También aparecen bolardos colocados transversalmente a las aceras donde se ubican vados vehiculares de acceso a los edificios, y en las esquinas de las intersecciones a nivel para delimitar el radio de giro de los vehículos.

Si bien los bolardos cumplen una función de limitación y protección, en ocasiones pueden representar más un estorbo que una solución. Por esta razón, su introducción en el espacio público debe realizarse con precaución. En nuestro caso, pueden generar ciertos problemas con la apertura de las puertas de los vehículos que dan hacia la acera, ya que los estacionamientos laterales se mantienen a lo largo de toda la plataforma única. Además, en ocasiones se aplican de manera excesiva, restringiendo no solo el paso de vehículos, sino también obstaculizando el propio flujo peatonal.

\section{El diseño del suelo y la crisis de una identidad urbana}

Evidentemente, hasta ahora no hemos reflexionado sobre el pavimento. Se debe a que este, por su importante papel en la configuración del paisaje urbano, merece su propio apartado.

El pavimento se convierte en un elemento de "escenificación urbana" (Cullen, 1971: 128) conforme a los valores estéticos que se le otorgue. Este, en conjunto con otros elementos del paisaje urbano, también puede afectar la imagen mental que los ciudadanos tienen de su ciudad, produciendo lugares que perciben como "inolvidables" (Lynch, 1960: 125). En ese sentido, el pavimento puede entenderse como una parte esencial en la creación de la 
identidad de los lugares (Brandão, 2011: 55).

"Las posibilidades de ornamentación, el color y la textura de los materiales son cualidades visuales del pavimento que desempeñan un papel fundamental en la imagen de la ciudad. Estas cualidades visuales participan en los procesos de identidad de la ciudad, en la medida en que se generaliza un tratamiento común del espacio público [...]" (Esparza, 2017: 273).

De aquí en adelante vamos a partir de la premisa de que existen dos tipos de pavimentos según su aplicación en la ciudad: los de uso extensivo y los de uso intensivo (Remesar, 2017: 11). Los primeros son aquellos que generalmente se encuentran repetidos a lo largo de toda la ciudad, como un elemento relevante que configura la imagen global de la propia ciudad. De allí que se usen de forma extensa. Los segundos son los pavimentos que se colocan de manera puntual para dotar a un lugar, una calle o una plaza de cierta singularidad para que pueda diferenciarse de otros lugares. Haciendo énfasis en la importancia de los pavimentos de uso extensivo, Lecea (2006: 32) señala que

"[...] salvo actuaciones puntuales [intensivas], el pavimento de la ciudad deberá entenderse como un proyecto global [a través de su uso extensivo], en un proceso que debe ser respetuoso y coherente con la ciudad ya construida. Un proyecto sobre la ciudad raramente nace de nuevo, se incorpora a un marco ya construido del cual constituye una parte sin duda pequeña, un marco que nos aparece en la memoria cuando recordamos las imágenes de una ciudad".

De acuerdo con los enunciados de Brandão (2011: 40-41), podemos establecer que el espacio público, como "matriz de la urbanidad", contiene cinco dimensiones de identidad: la morfológica, la visual-perceptiva, la vivencial-funcional, la socialcultural y la económica-legal. Dentro de la dimensión visual-perceptiva, Brandão hace referencia a la constitución de los lugares singulares versus los genéricos en la ciudad:

"Los espacios icónicos y simbólicos se pueden distinguir de los lugares indistintos (que injustamente llamamos no-lugares), pero no todos los lugares pueden ser excepcionales, ya que la calidad genérica del espacio público también es identitaria".

Vemos, entonces, que aparecen dos escalas de identidad: la de los lugares singulares que hallamos en diferentes puntos, y la de la ciudad como un organismo que alcanza cierta homogeneidad a través de elementos que se repiten en el espacio público y que generan una imagen de conjunto. En ambos casos el pavimento puede ser utilizado como un material para la construcción de esas identidades, ya sea a través de la repetición extensiva en toda la ciudad o de la diferenciación intensiva de determinados lugares. 
Una lectura rápida del pavimento de la ciudad de Panamá nos permite observar que no existe una imagen de conjunto establecida por una política urbana. El esquema general presenta un panorama de deterioro sistemático del espacio público con poca calidad visual y perceptiva: aceras asépticas, privatización y especialización, alta ocupación por el vehículo privado y en ocasiones simple desaparición de la calle (sobre todo en las periferias, pero el centro no es la excepción). Esto viene de décadas de producir el espacio público como un elemento "que sobra" de los emprendimientos inmobiliarios (Cabrera, 2012: 35), lo que, en gran medida, se debe a que las políticas de desarrollo urbano en Panamá benefician ampliamente al capital por sobre el interés común (Carrera, 2019: 8).

Así, el pavimento, en su forma extensa como un elemento que "tiñe" el espacio público, tiende a perder valor dentro del proceso de la construcción de una imagen de la ciudad. Su consolidación y repetición, sin embargo, son cualidades relevantes no solo para la construcción de una imagen global, sino que también contribuyen en la identificación de los espacios singulares:

"Podemos afirmar que esta repetición" [del pavimento] es, en buena medida responsable por la creación de una "proto-imagen", una imagen común para toda la ciudad. Mediante una serie finita de elementos se consigue la apropiación del territorio, de su conjunto, de la ciudad toda, y no sólo de los territorios vinculados con la experiencia directa del espacio, lo que permite establecer una pauta "común" que ayuda a destacar las diferencias" (Remesar y Esparza, 2012: 121).

En este contexto teórico, podemos inducir, con un simple ejercicio de observación, que el ejercicio de pavimentación en vía Argentina se trata de una actuación singular por sus claras intenciones de diferenciarse de otras calles y de generar una identidad propia. Su pavimento es de uso intensivo. Sin embargo, esta singularidad de vía Argentina (como un lugar) en relación a la ciudad de Panamá (como conjunto global) se produce más por ausencia en la definición de una política de pavimentación para toda la ciudad ${ }^{11}$, y no tanto por diferenciación de una pauta común, ya que no existe. El nuevo pavimento en las aceras de vía Argentina utiliza dos lógicas distintas. Primero, encontramos una serie de losetas y adoquines de colores en las secciones de calle convencional. En cambio, en la pavimentación de las plataformas únicas se utilizan losas de hormigón coloreado de mayor tamaño.

10.- Remesar y Esparza (2012: 121) utilizan el ejemplo de la repetición del "panot" en las aceras de Barcelona, un pavimento gris de 20 × 20 centímetros que se extiende a lo largo de toda la ciudad y en conjunto genera "una textura visual muy particular".

11.- En el último Plan Local de Ordenamiento Territorial del Distrito de Panamá, aprobado en 2021, se señala que las "especificaciones de materiales, detalles constructivos, especies de árboles y mobiliario a utilizar en la acera serán definidas por el Municipio de Panamá", lo que podría servir como base para la creación de una política de pavimentación extensiva. El acuerdo puede consultarse en www.gacetaoficial.gob.pa bajo el número 29268 A. 


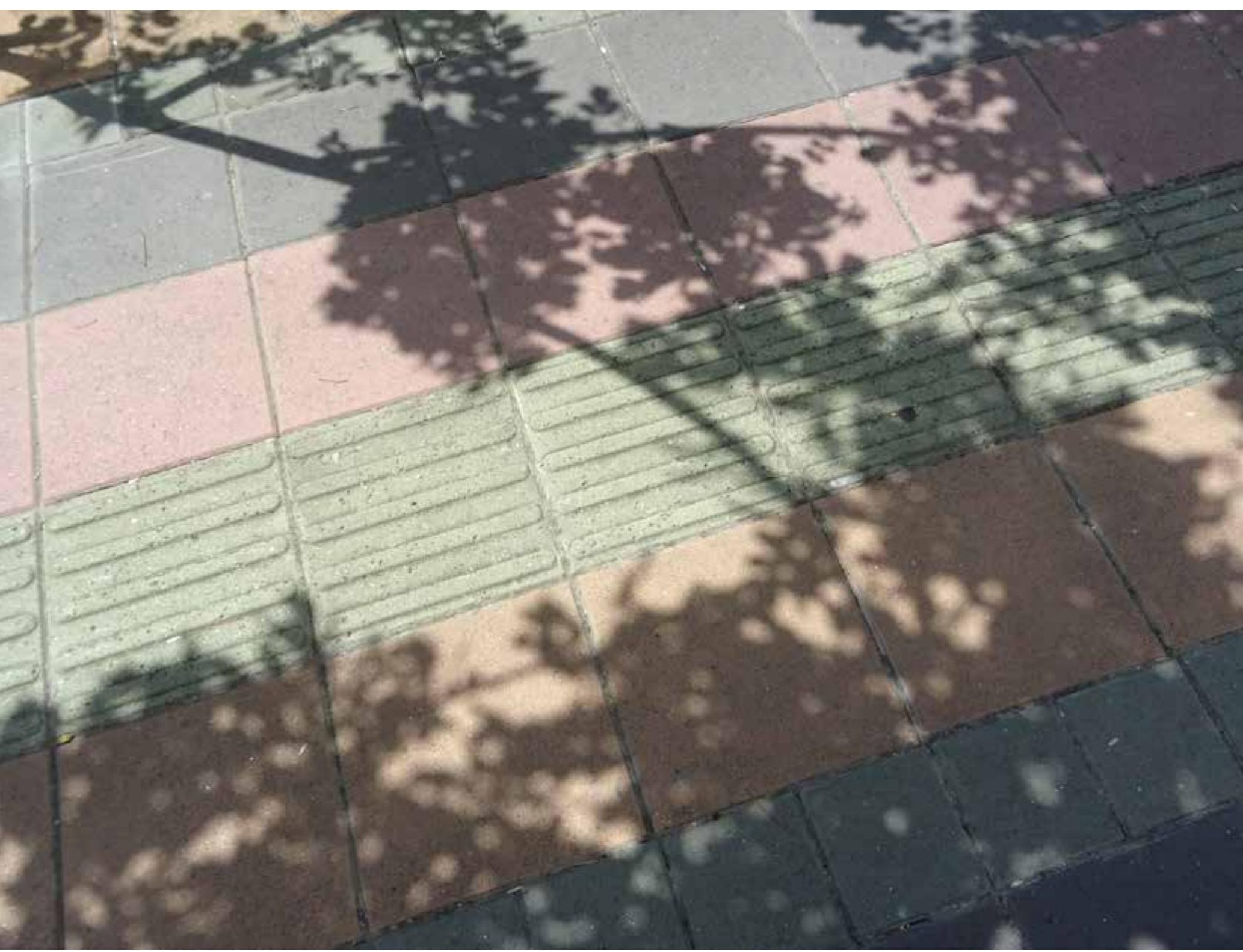

Fig. 15. Acercamiento a la configuración del pavimento en la sección de calle convencional en vía Argentina. Fuente: fotografía del autor.

En el primer caso se emplean losetas de hormigón de 40 × 40 centímetros y adoquines de 20 × 20 y 20 x 10 centímetros, todos con 6 centímetros de espesor. Cada una de estas piezas puede presentarse en seis colores distintos (dos tonos de verde, naranja, siena, negro y beige), y su colocación varía a lo largo de toda la calle, generando una serie de diferentes patrones que juegan con el tamaño y el color de las piezas. Estas combinaciones pueden ser tan variables que, en cierta medida, se dificulta la lectura del conjunto del pavimento. Además, esta configuración de combinaciones basadas en colores y tamaños diferentes puede generar otra serie de problemas a medida que el proyecto envejece y requiere de mantenimiento:

"[El proyectista] podrá encontrar un repertorio muy amplio de materiales, modelos o colores alternativos pero, al final, se dará cuenta [...] de que una vez se colocan en la calle, en el espacio público, todos los pavimentos acaban viéndose blancos, negros o grises y que los juegos de color, y muchas veces 


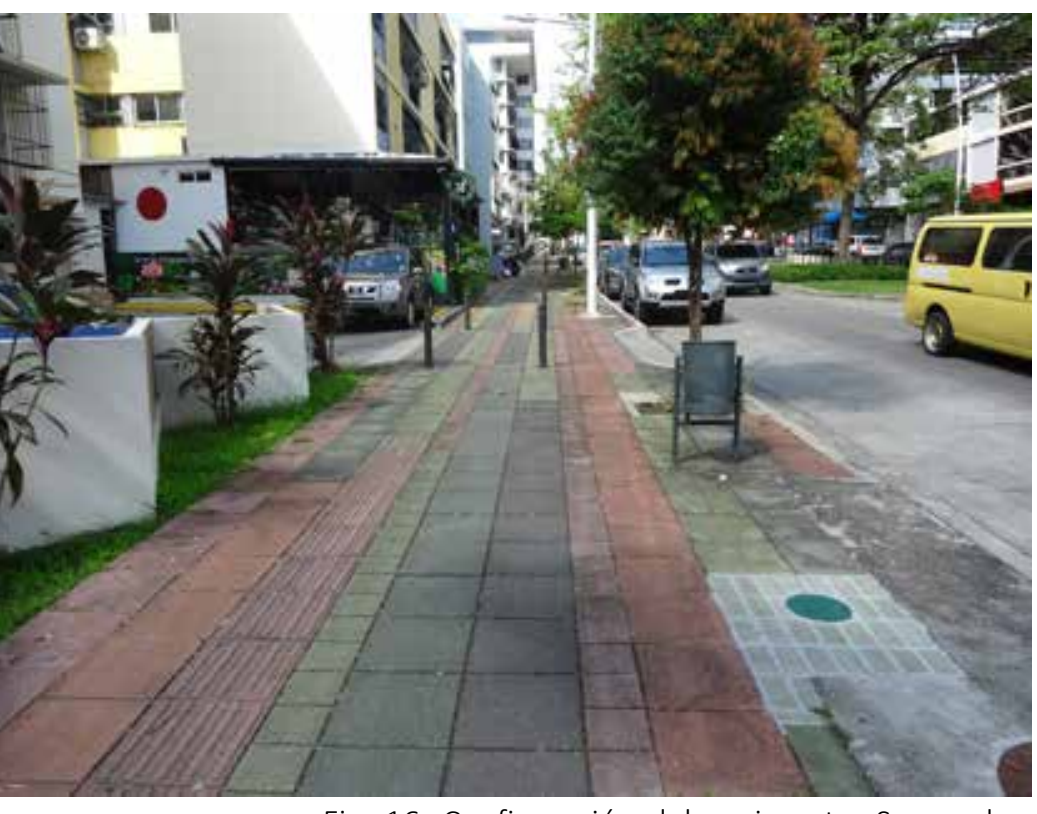

Fig. 16. Configuración del pavimento. Se puede observar cómo empieza a aparecer el efecto de patchwork desde muy temprano con la reposición de algunas piezas. Fuente: fotografía del autor.

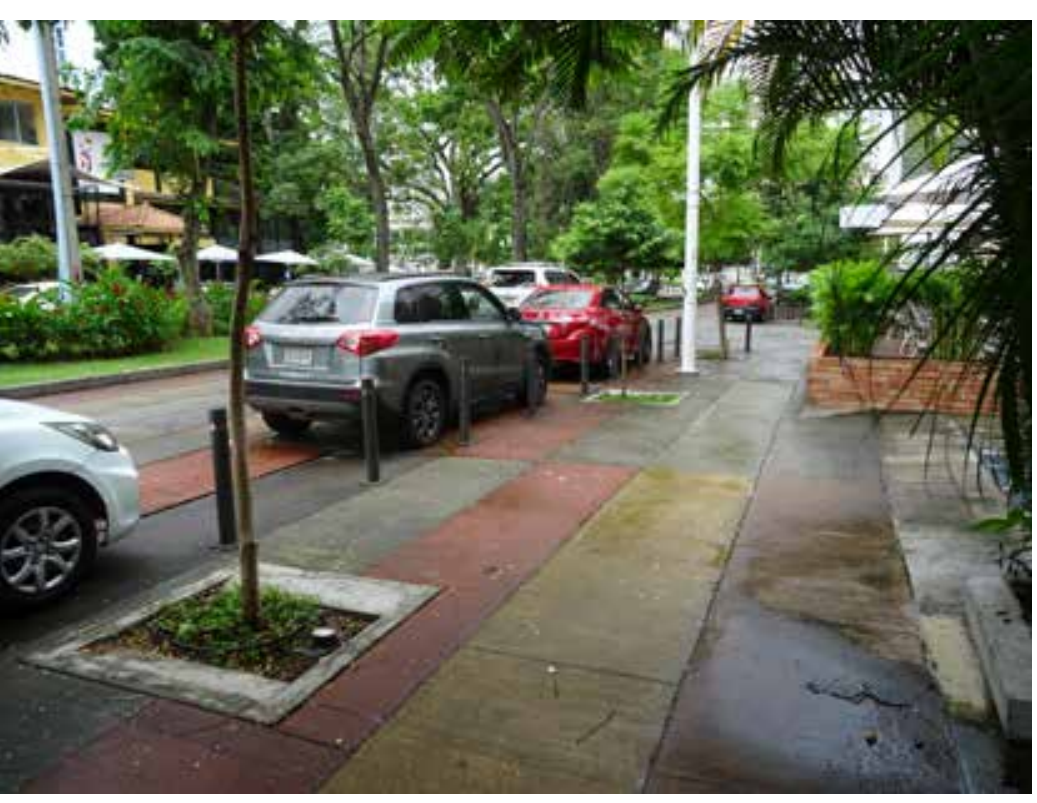

Fig. 17. Pavimento mojado en plataforma única. Fuente: fotografía del autor. también los de aparejo o despiece, tan solo se apreciarán cuando el pavimento esté mojado. Con el paso del tiempo las dificultades de reposición acabarán configurando una especie de patchwork de diferentes tonalidades, y el pavimento que se pretendía singular -en el buen sentidoacabará siéndolo -pero en el mal sentido-" (Lecea, 2006: 34).

En el caso de las intersecciones a nivel y los 300 metros de calle que se configuran como plataforma única se utiliza una lógica distinta en la pavimentación. Se emplean losas de hormigón con acabado barrido, coloreado (al igual que las losetas y adoquines), de $1.20 \times 0.80$ metros (aunque en ocasiones puede variar) $y$ unos 20 centímetros de espesor ya que deben soportar el peso de los vehículos. Las losas se colocan con orientación transversal al eje de la calle en los cruces, y en el resto de forma longitudinal.

El juego de combinaciones de colores se mantiene, pero sin una variación evidente en el tamaño de las piezas. El cambio más significativo se produce en el tramo inmediato al parque Andrés Bello donde el pavimento del parque se proyecta hasta la calle, aumentando considerablemente su tamaño. De esta manera, el diseño del suelo se unifica entre la totalidad de la calle. Es decir, en las intersecciones y en el resto de la plataforma única, el pavimento es el mismo para la acera y la calzada, resultando en un plano horizontal homogéneo en términos de textura, nivel y color para vehículos y peatones. 
Ahora, tras una mirada al diseño del suelo, veremos que este tratamiento igualitario del pavimento, aunque bienintencionado a primera vista, puede resultar ambivalente en relación con los nuevos parámetros de accesibilidad que pretende establecer el proyecto.

\section{La accesibilidad en proyectos de espacio público}

Reconocemos la amplitud y profundidad con la que puede ser discutida la accesibilidad, como lo han hecho Remesar y Vergel (2020: 41-43) al categorizarla como un mecanismo para el ejercicio efectivo del derecho a la ciudad. Sin embargo, por el enfoque teórico-proyectual de este artículo vamos a utilizar una concepción más puntual de ella. Nuestra intención ahora no es reducir el concepto de accesibilidad, sino ilustrar algunos aspectos formales en la configuración de la calle que condicionan su uso en un sentido físico.

Siguiendo la construcción teórica de Remesar y Vergel, señalan que la accesibilidad, como "uno de los modos de promover la inclusión y cohesión social", se ha abordado tradicionalmente de dos maneras. Primero: desde la movilidad y el transporte, a través de la geografía o la planificación urbana. Y segundo: desde la usabilidad y funcionalidad del entorno, mediante el urbanismo, el diseño urbano o la arquitectura. Nos mantendremos en la línea de la segunda orientación, precisamente la de la accesibilidad universal.

En nuestro caso de estudio, los criterios para conseguir un entorno accesible se persiguen a través de la eliminación de las barreras o límites verticales en la calle mediante el uso de la plataforma única. Este esquema se presenta, como hemos señalado, en las seis intersecciones presentes y en el tramo central de la vía más próximo al parque Andrés Bello, de manera que los principales cruces peatonales se mantienen siempre en la misma cota. Como resultado, aproximadamente un $40 \%$ del recorrido total de la calle se configura de esta manera. Ahora, una calle en plataforma única puede responder a distintas tipologías según su configuración, usos y relaciones. Por tanto, es valioso definir de qué estamos hablando cuando hacemos referencia de este modelo.

Una calle en plataforma única es aquella en la que se han suprimido todos los cambios de nivel, resolviendo la totalidad de la calle en un plano único. De aquí en adelante se clasifica en varios tipos según cómo se distribuyan los usos. Este paradigma puede presentarse tanto en calles completamente peatonales, como en calles por donde circulan peatones y vehículos. Cuando el caso es el último nos referimos a una plataforma única de uso mixto. Así mismo, las plataformas únicas de uso mixto se pueden ordenar en base a cómo se han establecido las relaciones de circulación entre 


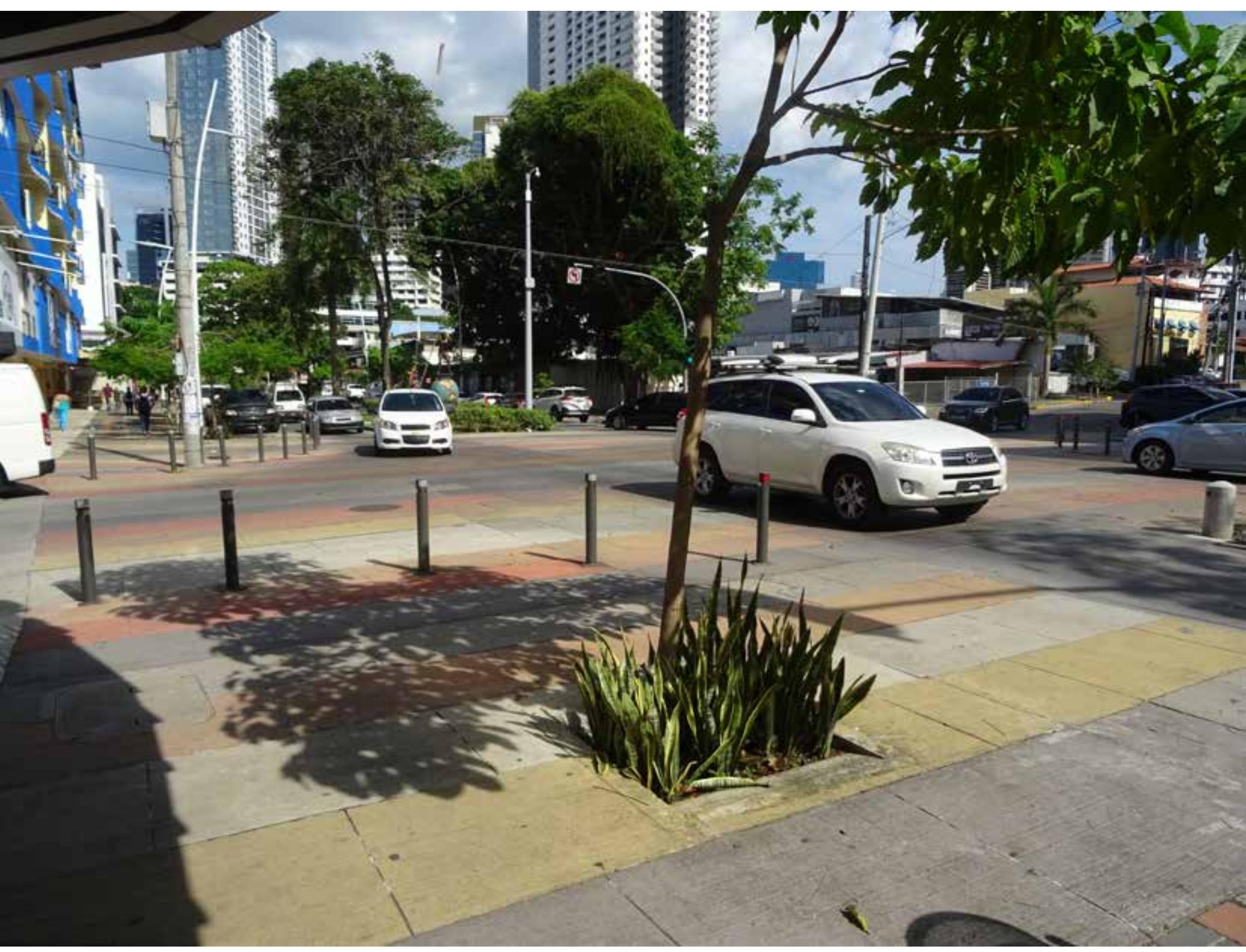

Fig. 18. Una de las seis intersecciones o cruces en donde la calzada se levanta al nivel de la acera. Fuente: fotografía del autor.

los distintos usuarios de la calle: pueden ser espacios de convivencia (donde peatones y vehículos comparten el mismo espacio, recibiendo los peatones la prioridad de circulación), o pueden ser espacios de coexistencia ${ }^{12}$ (donde peatones y vehículos circulan por franjas diferenciadas al mismo nivel).

Con estas definiciones podemos determinar que en vía Argentina no se configuran espacios de prioridad peatonal, sino que se trata de una plataforma única de uso mixto como espacio de coexistencia, donde peatones y vehículos disponen de franjas específicas para su circulación. En este caso el bordillo es reemplazado por la repetición continua del bolardo

12.- Jiménez (2015: 21) define lo espacios de coexistencia como lugares donde "existen "otras delimitaciones" diferentes a la barrera del bordillo o diferencia de cota (como son los elementos urbanos o los propios pavimentos), que conllevan a un uso de ese espacio por áreas diferenciadas. Es decir, el espacio aparentemente continuo tiene un uso diferenciado en unas zonas y en otras. Los vehículos y peatones coexisten en un espacio único, pero no comparten el espacio ya que cada uno utiliza sólo una parte del mismo". 
como elemento diferenciador, apoyado por el eje de estacionamientos laterales en la calle que también separa al peatón de los vehículos en movimiento. Sin embargo, aunque los usos estén delimitados parcialmente, los peatones no están exentos de tener que lidiar con los vehículos en ciertas ocasiones, y cuando estas relaciones no están bien resueltas pueden surgir una serie de conflictos. Tal es el caso en el que el peatón decida cruzar la calle, ya sea transversalmente o cuando se acerque a una de las intersecciones en el camino.

La plataforma única ha llegado a ser considerada por lo opinión pública como el modelo de la accesibilidad en el espacio público de la actualidad, usualmente por una asociación muy literal de la "supresión de barreras" con el "diseño para todos". No obstante, se tiende utilizar una concepción sobre un tipo de peatón muy particular (generalmente asociado al uso de la silla de ruedas) al momento de diseñar el entorno de este modelo, dejando de lado la diversidad funcional de todas las personas que en la práctica utilizan el espacio público (Jiménez, 2015: 2-5).

Sin pretender nombrar cada caso específico de interacción entre peatones y el modelo de plataforma única (que ya algunos deben ser evidentes), vamos a profundizar en conceptos básicos que deben estar presentes al momento de configurar estos espacios.

En ese sentido, Alonso (2007: 17) señala que no es necesario referirse a colectivos concretos al tratar la accesibilidad, ya que todas las personas en algún momento de su vida tendrán necesidades singulares en su relación con el entorno (por vejez, niñez, embarazo, accidentes o enfermedades). Por esta razón, para construir entornos realmente accesibles, "la asociación automática de accesibilidad con barreras y discapacidad, debe ser superada para desplegar todo su significado y beneficios en relación con todo tipo de personas" (Alonso, 2007: 17). Se entiende entonces que nos referimos a una población en su totalidad. Todos los ciudadanos, sin distinciones, como lo ha explicado Lecea:

"[...] la accesibilidad pasa a ser uno de los requisitos esenciales, un punto de partida, esencial en las bases de [todo] proyecto, entendiendo que la accesibilidad no afecta tan solo a la estricta minoría de personas con disminución sino al conjunto de los ciudadanos, que de hecho se trata de una cuestión que se refiere al confort de la ciudad" (Lecea, 2006: 54).

El colectivo catalán "Carrers per a tothom" (en español "Calles para todas las personas") ha logrado establecer algunos criterios sobre accesibilidad en cuanto a la implementación de la plataforma única de uso mixto, como la de vía Argentina. El colectivo señala que el uso de este modelo suele relacionarse con una voluntad de dar prioridad al peatón sobre los vehículos y así "pacificar" el tráfico en la calle, aunque muchas veces esa buena voluntad termina siendo más hipotética que real: 
"[...] lejos de intentar cumplir el primer objetivo de mejora de la accesibilidad [...], este modelo de calle se ha convertido en un modelo que fomenta la inseguridad (tanto para los peatones como para los vehículos que circulan), el riesgo, la desorientación de muchas personas con discapacidad y de muchos otros colectivos ciudadanos" (Carrers per a tothom, 2015: 5).

Para ellos, la plataforma única debe reservarse exclusivamente como una herramienta para mejorar la accesibilidad en aquellas calles que, por su anchura muy reducida ${ }^{13}$ (como algunas en nuestros centros históricos), no cuentan con suficiente espacio para establecer circulaciones vehiculares e itinerarios peatonales coherentes y diferenciados. Por esta razón agregan que

"unido a la evidencia de que se ha implantado el diseño de la plataforma única de uso mixto en muchas calles que, dada su anchura y configuración, no la requerían para mejorar su accesibilidad [...], nos hace pensar que el uso de esta solución urbanística responde a unas razones probablemente estéticas más que de usabilidad, comodidad y seguridad ciudadana" (Carrers per a tothom, 2015: 5).

En todo caso, Carrers per a tothom (2015: 9-21) ilustra una serie de parámetros que deben cumplirse cuando se utilice el paradigma de la plataforma única de uso mixto. Estos criterios, algunos con objetivos claros y otros con finalidades muy específicas, pueden servir como base para comprobar la validez y seguridad que ofrece la plataforma única en nuestro caso de estudio. Aunque desde un principio los parámetros sugieren que, vía Argentina, con sus 25 metros de anchura, no debería utilizar este modelo al contar con suficiente espacio para disponer de itinerarios peatonales y vehiculares separados con diferencia de nivel. Si fuera así el caso, los cruces habrían de resolverse con vados peatonales, lo que ofrecería la oportunidad de poner en valor este elemento primario, cuya importancia suele desestimarse en la construcción de la calle y el espacio público de la ciudad. En fin, entre los criterios más relevantes podemos mencionar los siguientes:

Primero, se establece que debe existir una franja de pavimento podotáctil (de botones) que delimite todo el perfil de la calzada y la acera, con una anchura de por lo menos 60 centímetros $^{14}$. Este elemento funciona como un "aviso" de cambio de uso en la calle, fácilmente detectable por bastones y otros instrumentos de ayuda. En segundo lugar, se sugiere que exista un contraste cromático ${ }^{15}$ entre el espacio dedicado a los peatones y el dedicado a los vehículos, de forma que se pueda percibir fácilmente por dónde circula cada uno. Tercero, se debe limitar la velocidad de tránsito al mínimo

13.- Carrers per a tothom (2015: 9) considera que la plataforma única de uso mixto debe implementarse sólo en calles con una sección menor a 8 metros.

14.- Como referencia, estos elementos podemos encontrarlos en las estaciones del Metro de Panamá colocados entre los andenes y las vías del metro.

15- Esparza (2014: 23), cuando reflexiona sobre la relación entre la accesibilidad y el pavimento, también argumenta que estos deben poder señalar los paseos de peatones con texturas diferenciadas. 
anteriormente. La arborización mejoró, el tráfico y los estacionamientos se ordenaron, la acera se consolidó y en general el proyecto promovió la creación de una imagen urbana del barrio. Es decir, la calle se cualificó en términos de diseño urbano, lo que nos permite reconocerla ahora como espacio público.

El gesto quizás más importante en el proyecto fue el de establecer un sistema de elementos primarios de urbanización para consolidar el espacio público. La aplicación de este sistema permitió recuperar el espacio que los vehículos y otros elementos ocupaban injustamente. Este acto permite que vía Argentina ya no sea solo una simple vía de conexión en la exópolis ${ }^{17}$ que es la ciudad de Panamá, sino también un lugar donde pueden ocurrir otras actividades como el encuentro y el descanso (Remesar y Ricart, 2013: 16). Sin embargo, esto no significa que todo esté resuelto de la mejor forma, como bien hemos ilustrado.

En términos de distribución espacial, el espacio para los vehículos motorizados sigue ocupando una parte considerable de la sección de la calle en comparación con el espacio dedicado a los peatones. Esto es debido a dos cuestiones: que el proyecto haya decidido conservar la mediana central (o que no se haya reducido en dimensión), y que los estacionamientos laterales se hayan mantenido del mismo tamaño que un carril de transito regular ${ }^{18}$, ofreciendo un espacio bastante holgado para la circulación de los vehículos.

Si bien mencionamos que la aplicación de los elementos primarios de urbanización representa una mejora considerable para la calle, quedan detalles por resolver, como algunos relacionados a la ejecución del proyecto. Un ejemplo es el de la ubicación de los alcorques con respecto al esquema modular del pavimento, que en ocasiones están colocados bajo una lógica coherente, pero en otras se ubican de forma deliberada, teniendo que hacer modificaciones en losetas y adoquines que pueden afectar su durabilidad. Por esto es importante que todos estos elementos sean considerados dentro de un sistema único donde se complementen los unos con los otros. Podemos hacer mención también del bordillo, que por su método de fabricación presenta dimensiones variables, cuando debería ser un elemento uniforme de transición entre la acera y la calzada.

La pavimentación de las aceras en vía Argentina es definitivamente una mejora a lo que se presentaba anteriormente, principalmente porque se unifican los recorridos peatonales y se pavimenta desde el bordillo hasta la fachada (aunque a veces desde la fachada al bordillo). Sin embargo, el juego aparente en las combinaciones de tamaños y colores del pavimento puede traer problemas en cuanto a su mantenimiento,

17.- Para Remesar y Ricart (2013: 11), una "exópolis" es una ciudad fragmentada, donde la relación entre los diferentes espacios se produce principalmente mediante la "cápsula de la esfera privada que es el automóvil", y el espacio público se reduce a simples vías de conexión.

18.- Los planos del proyecto indicaban que los estacionamientos laterales serían de 2.20 metros de ancho, sin embargo, luego de comprobarlo en varios puntos, en la práctica se mantuvieron de 3 metros aproximadamente. 
como es la reposición precisa de las piezas, que al mismo tiempo desencadena otros problemas en términos de diseño e imagen, como la aparición de parches y contrastes no deseados entre piezas viejas y nuevas.

El pavimento de uso intensivo aparece como una herramienta importante para dotar a vía Argentina de una identidad propia. De todos modos, es valioso mencionar que la singularidad de una calle no se limita sólo a su pavimento, aunque esta suele ser la estrategia más generalizada. Otros gestos como poner en valor la propia arquitectura del lugar (que en vía Argentina puede considerarse icónica ${ }^{19}$ ), redimensionar algunos elementos primarios o estructurar elementos especiales que ocupen el plano del aire como los árboles o las farolas son acciones capaces de dotar a la calle de singularidad, lo que permite mantener cierta homogeneidad material en el plano del suelo.

Aun así, vale la pena reflexionar sobre el uso desmedido de la pavimentación intensiva en distintos puntos de la ciudad, pues, como explicaba Brandão (2011: 40), no todos los lugares pueden ser icónicos, ya que el carácter común del espacio público es el que produce la identidad del conjunto de la ciudad. La ausencia de una definición de una política de pavimentación para toda la ciudad de Panamá invita a proyectistas a explorar posibilidades singulares en cada intervención. Una forma de promover el hacer "cualquier cosa en cualquier lugar", lo que genera una infinidad de proyectos singulares aislados que poco tienen que ver los unos con los otros, y menos con la ciudad como conjunto. Se vuelve una tarea urgente el definir una pauta común del espacio público.

Esta disyuntiva no se limita solo al pavimento, sino también al sistema de los elementos primarios de urbanización. Se encuentra muy a menudo elementos fabricados de manera artesanal en el espacio público que suelen ser inconsistentes, como sucede con los vados o bordillos cuyo mantenimiento es seguramente muy complicado. Su estandarización en el espacio urbano permitiría ofrecer un repertorio de soluciones comunes para toda la ciudad, además de simplificar su mantenimiento y asegurar la existencia de reposiciones futuras (Esparza, 2017: 221).

En cuanto a la accesibilidad, es evidente que el pavimento juega un papel importante en la lectura y usabilidad del espacio público. El tratamiento igualitario para franjas peatonales y vehiculares sin elementos de aviso, contraste cromático o diferenciación de texturas produce una serie de conflictos que la propia plataforma única pretende resolver al eliminar la diferencia de nivel. Es decir, se suprimen las barreras, pero se generan otros problemas.

La voluntad de colocar las intersecciones a nivel de la acera compartiendo el mismo pavimento, crea a primera vista una especie de "plaza dura abierta" en los cruces. Sin embargo, puesto que no se ha restringido el tráfico ni se han formalizado los 19.- En vía Argentina y en su alrededor se encuentra una gran muestra de edificios residenciales de corte moderno, mediana escala y grandes balcones, representativos de la arquitectura de principios de la segunda mitad del siglo XX en Panamá. 


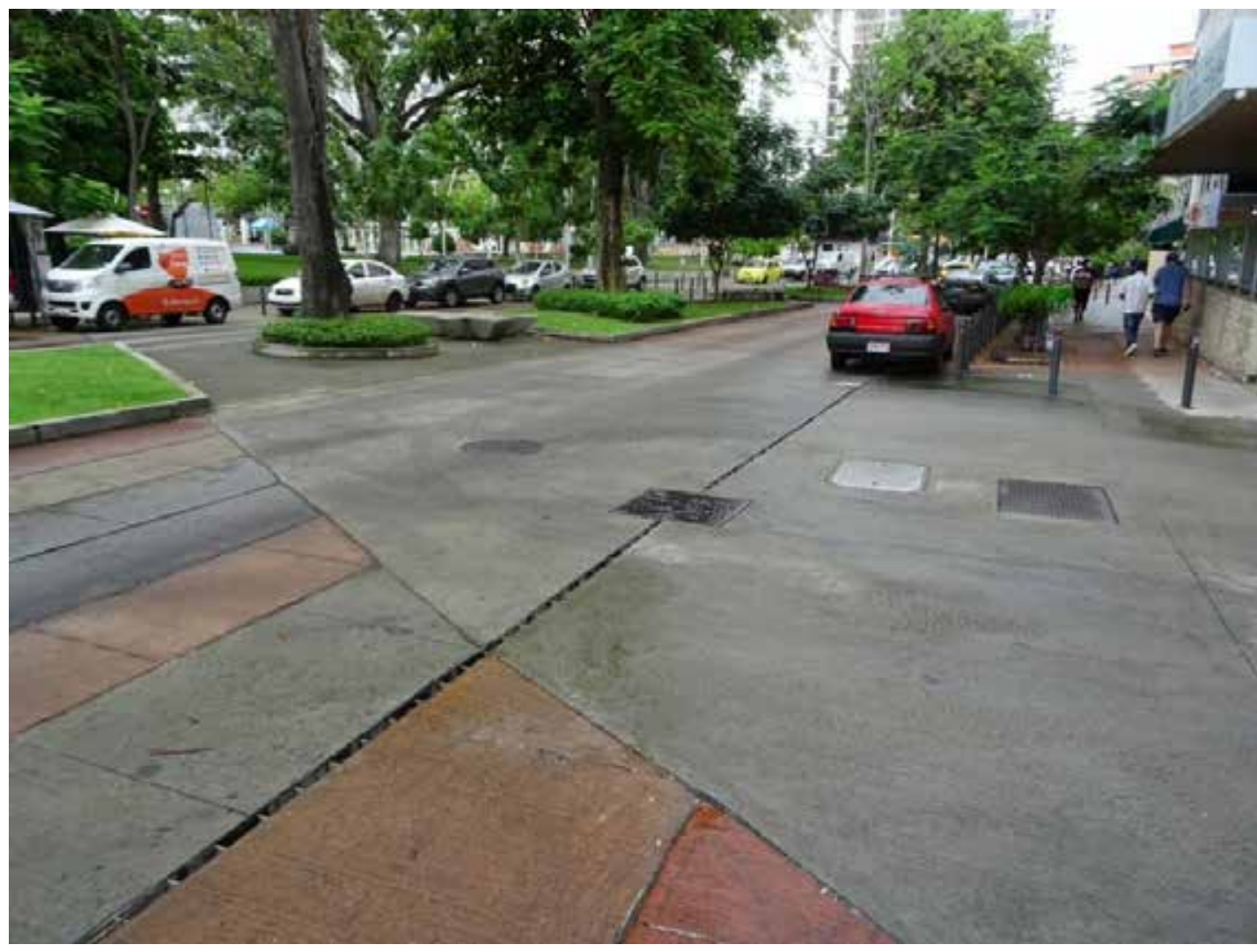

Fig. 23. Pavimento de gran escala en plataforma única frente al parque Andrés Bello. Fuente: fotografía del autor.

cruces peatonales, estos espacios se convierten en lugares de convivencia temporal dominados completamente por los vehículos.

Ciertamente, el hecho de que vía Argentina se convierte en una calle híbrida en la configuración del plano horizontal, de forma que una parte del recorrido se realiza en plataforma única y la otra de manera convencional, parece indicar que se trata en realidad de un gesto basado en tendencias puramente estéticas, que de confort y seguridad. Una evidencia importante es que el tramo en plataforma única es el más próximo al parque Andrés Bello, donde este se "abre" al entorno y lleva su pavimento de "gran escala" a la calle entera. Donde sucede esto se crean espacios equipados con mobiliario en algunas secciones de la mediana central, los cuales aparentan ser zonas de cruce peatonal, pero reproducen los problemas ya mencionados.

En estos lugares, por su superficie homogénea, el diseño del suelo sugiere que se trata de un espacio donde el peatón tiene libertad de uso sobre todo el espacio. Esta aplicación es típica de las plataformas únicas de uso mixto diseñadas como espacio de convivencia (donde previamente se ha restringido y pacificado el tráfico), pero en realidad nuestro caso responde a un espacio de coexistencia donde todavía es necesario tener cuidado con los vehículos, sobre todo en los puntos de cruce. El diseño del suelo no debe ser excluyente de los criterios básicos de accesibilidad, cuestión que ya debería estar superada en todo nuevo proyecto de espacio público.

En definitiva, el nuevo paisaje urbano de vía Argentina propone una formalización 
del espacio público frente al deterioro sistemático de las calles en ciudad de Panamá. No obstante, queda todavía pendiente repensar las formas en las que la calle prioriza la movilidad peatonal, prestar atención a las decisiones que influyen en la creación de la identidad de los lugares y cuidar los detalles propios de la construcción física y simbólica del espacio público para asegurar un entorno coherente, significativo y duradero.

\section{Bibliografía}

ALONSO, Fernando (2007). Algo más que suprimir barreras: conceptos y argumentos para una accesibilidad universal. TRANS. Revista De Traductología, (11), 15-30. Disponible en: https://doi.org/10.24310/TRANS.2007.v0i11.3095

BORJA, Jordi (2013). Revolución urbana y derechos ciudadanos. Madrid: Alianza Editorial.

BRANDÃO, Pedro (2011). La imagen de la ciudad. Estrategias de identidad y comunicación. Barcelona: Edicions de la Universitat de Barcelona.

BRANDÃO, Pedro (2014). Diseño urbano e interdisciplinariedad. on the w@terfront. Public Art. Urban Design. Civic Participation. Urban Regeneration, 0 (29), 58-72. Disponible en: https://revistes.ub.edu/index.php/waterfront/article/view/18843

CABRERA, Magela (2012). Espacio público y derecho a la ciudad. Tareas, 141, 31-57. Disponible en: https://www.redalyc.org/articulo.oa?id=5350/535055524003

CALATRAVA, Juan (2016). El París de Haussmann como territorio de la utopía: Victor Fournel (1865) y Victor Hugo (1867). Quintana. Revista de Estudos do Departamento de Historia da Arte, (15), 53-71. Disponible en: https://www.redalyc.org/articulo.oa?id=65354336005

CARRERA, Azael (2019). El derecho a la ciudad en la época del 'urbanismo neoliberal'. Tareas, 161, 5-14. Disponible en: https://www.redalyc.org/articulo. oa?id $=5350 / 535058540002$

CARRERS PER A TOTHOM (2015). Queremos unas calles que sean de verdad para todas las personas. Barcelona: Plataforma ciudadana 'Carrers per a tothom'.

CARRIÓN, Fernando (2016). El espacio público es una relación, no un espacio. En: Ramírez, P. (coord.) La reinvención del espacio en ciudad fragmentada. México: UNAM, Instituto de Investigaciones Sociales, Programa de Maestría y Doctorado en Urbanismo, 13-47.

CULLEN, Gordon (1971). El paisaje urbano: tratado de estética urbanística. Barcelona: Editorial Blume.

DE GRACIA, José (2020). Una perspectiva urbana de la pandemia en Panamá. on the w@ terfront. Public Art. Urban Design. Civic Participation. Urban Regeneration, 62 (8), 3-26. Disponible en: https://doi.org/10.1344/waterfront2020.62.6.12

ESPARZA, Danae (2014). El diseño del suelo: el papel del pavimento en la creación de la imagen de la ciudad. Tesis (Doctoral), Programa de Doctorado Espacio Público y Regeneración Urbana (Universitat de Barcelona). Disponible en: http://hdl.handle. net/10803/146248

ESPARZA, Danae (2017). Barcelona a ras de suelo. Barcelona: Edicions de la Universitat de Barcelona.

HARVEY, David (2013). Ciudades rebeldes. Del derecho de la ciudad a la revolución urbana. Madrid: Ediciones Akal. 
HENRICH, Jordi, \& PEREIRA, María (2019). Jordi Henrich. Una visión de Barcelona y su espacio público. on the w@terfront. Public Art. Urban Design. Civic Participation. Urban Regeneration, 61 (2), 3-50. Disponible en: https://doi.org/10.1344/waterfront2019.61.6.2

IGLESIAS, Manuel (2016). Materiales del espacio público urbano. ¿Mantenimiento y diseño? on the w@terfront. Public Art. Urban Design. Civic Participation. Urban Regeneration, 48, 7-20. Disponible en: https://revistes.ub.edu/index.php/waterfront/article/view/18674

JIMÉNEZ, Delfín (2015). La accesibilidad en los espacios públicos con plataforma única de convivencia. Análisis y Clasificación de las soluciones existentes. Avances y nuevos problemas. Posibles parámetros e Indicadores de Accesibilidad. Tesis (Doctoral), E.T.S. Arquitectura (UPM). Disponible en: http://oa.upm.es/40009/

LECEA, Ignasi de (2004). Arte público, ciudad y memoria. on the W@terfront. Public Art. Urban Design. Civic Participation. Urban Regeneration, 0 (5), 5-17. Disponible en: https:// revistes.ub.edu/index.php/waterfront/article/view/18955

LECEA, Ignasi de (2006). Sobre el proyecto del suelo. on the w@terfront. Public Art. Urban Design. Civic Participation. Urban Regeneration, 0 (8), 30-104. Disponible en: https:// revistes.ub.edu/index.php/waterfront/article/view/18934/21396

LEFEBVRE, Henri (1972). La revolución urbana. Madrid: Alianza Editorial.

LYNCH, Kevin (1960). La imagen de la ciudad. Barcelona: Gustavo Gili.

MIRALLES-GUASCH, Carmen, \& CEBOLLADA I FRONTERA, Ángel (2003). Movilidad y transporte. Opciones políticas para la ciudad. Junio 17, 2003, de Fundación Alternativas. Disponible en: https://www.fundacionalternativas.org/laboratorio/documentos/ documentos-de-trabajo/movilidad-y-transporte-opciones-politicas-para-la-ciudad PIEDADE, Inês (2009). The interface, public space? Two cases. on the w@terfront. Public Art. Urban Design. Civic Participation. Urban Regeneration, 0 (12), 119-130. Disponible en: https://revistes.ub.edu/index.php/waterfront/article/view/18889

REMESAR, Antoni (2017). Presentación. Del diseño del suelo. En: Esparza, Danae. Barcelona a ras de suelo. Barcelona: Edicions de la Universitat de Barcelona.

REMESAR, Antoni, \& ESPARZA, Danae (2011). Imágenes congeladas. La imagen del centro histórico. En: Simposio Internacional de Urbanismo y Arquitectura. La Habana: Ministerio de Educación Superior - CUJAE.

REMESAR, Antoni, \& RICART, Nuria (2013). Reflexiones sobre el espacio público.on the w@ terfront. Public Art. Urban Design. Civic Participation. Urban Regeneration, 0 (25), 5-35. Disponible en: https://revistes.ub.edu/index.php/waterfront/article/view/18792

REMESAR, Antoni, \& VERGEL, Javier (2020). Acceder a la gestión de lo simbólico. Un derecho ciudadano. on the w@terfront. Public Art. Urban Design. Civic Participation. Urban Regeneration, 62 (7), 39-56. Disponible en: https://doi.org/10.1344/ waterfront2020.62.6.11

RODRÍGUEZ, Abdiel (2017). ¿'Gentrificación o rehabilitación urbana en la ciudad de Panamá? Tareas, (157), 123-126. Disponible en: https://www.redalyc.org/articulo. oa?id=535056123010

SENADIS (Sin fecha). Manual de Acceso. 3ra edición. Panamá: Secretaría Nacional de Discapacidad. Disponible en: https://www.senadis.gob.pa/documentos/recientes/manualde-acceso.pdf

STEMLEY, John J. (1998). One-way streets provide superior safety and convenience. ITE journal, $68(8)$, 47-50.

SUDIIC, Deyan (2017). El lenguaje de las ciudades. Barcelona: Editorial Ariel.

VALERA, Sergi (2011). La pérdida del espacio público: antídotos. En: La imagen de la ciudad. 
Estrategias de identidad y comunicación (11-13). Barcelona: Edicions de la Universitat de Barcelona.

\section{Reconocimientos}

Se le agradece al arquitecto Jose Isturaín por facilitar fotografías de la calle en el estado previo al proyecto de vía Argentina, las cuales contribuyeron a la elaboración de este artículo.

\section{(C) José Antonio De Gracia}

joseadgg@gmail.com

Universidad de Panamá

https://orcid.org/0000-0001-5551-9692

Arquitecto. Máster en Diseño Urbano por la Universidad de Barcelona.

Ha sido profesor de talleres de urbanismo y diseño en la Universidad de Panamá y la Universidad de Santa María la Antigua.

Ha trabajado en la Fundación Amador y en la empresa Luis Alfaro Arquitectura \& Paisaje, ambas en Panamá. Se dedica al ejercicio del diseño urbano y su investigación de manera independiente. 